Discussion Paper No. 16-030

\title{
Debt Deflation, Financial Market Stress and Regime Change - Evidence from Europe Using MRVAR
}

Ekkehard Ernst, Willi Semmler, and Alexander Haider

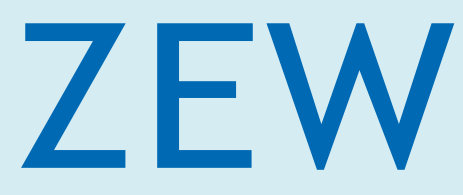

Zentrum für Europäische Wirtschaftsforschung $\mathrm{GmbH}$

Centre for European Economic Research 
Discussion Paper No. 16-030

\title{
Debt Deflation, Financial Market Stress and Regime Change - Evidence from Europe Using MRVAR
}

\author{
Ekkehard Ernst, Willi Semmler, \\ and Alexander Haider
}

Download this ZEW Discussion Paper from our ftp server:

http://ftp.zew.de/pub/zew-docs/dp/dp16030.pdf

Die Discussion Papers dienen einer möglichst schnellen Verbreitung von neueren Forschungsarbeiten des ZEW. Die Beiträge liegen in alleiniger Verantwortung der Autoren und stellen nicht notwendigerweise die Meinung des ZEW dar.

Discussion Papers are intended to make results of ZEW research promptly available to other economists in order to encourage discussion and suggestions for revisions. The authors are solely responsible for the contents which do not necessarily represent the opinion of the ZEW. 


\title{
Debt deflation, financial market stress and regime change - Evidence from Europe using MRVAR*
}

\author{
Ekkehard Ernst $\dagger_{\text {Willi Semmler }{ }^{\ddagger} \text { and Alexander Haider }}^{\S}$
}

February 28, 2016

\begin{abstract}
The economic meltdown since 2008-9 has created disinflation, and even deflation in some countries in the Euro-area, in a period with large debt overhang, creating the condition for a continuing financial market stress in the Euro-area. As disinflation and deflation push up the real interest rate, while growth and income declines, the leveraging problem becomes more severe and the economy risks shifting into a regime with high insolvency risk, high financial stress, rising credit spreads, possibly accompanied by strong adverse macroeconomic feedback loops. Investigating the consequences of those magnifying feedback loops, given the debt deflation, we demonstrate the possibility of unstable dynamics and downward spirals in the presence of regime-dependent macro feedback loops, using a theoretical model with decentralized matching mechanisms on both labor and financial markets. To explore the amplifying linkages between deflation, output, labor and financial markets, we employ a new solution procedure called NMPC to solve our models variants for out-of-steady-state dynamics. We empirically explore deflationary trends in Europe and employ a Global VAR (GVAR) model for a large euro area macro data set to estimate the impact of deflation on output. Moreover, we use a four variable Multi-Regime VAR (MRVAR) model with regime dependent IRs to study deflationary as well as well as the financial risk drivers in a MRVAR setting. New measures for financial risk drivers are employed and multi-regime IRs for output, inflation rates, interest rates and financial stress are explored. We also study regime changes in central macro relationships such as regime change in the credit - output link, the Phillips curve and in Okun's law.
\end{abstract}

\footnotetext{
${ }^{*}$ Research on this paper was undertaken when Willi Semmler was Visiting Researcher at the European Central Bank, Frankfurt, Winter 2014/15. He wants to thank the ECB for its hospitality. We want to thank Tony Bonen for excellent research assistance. A previous version of the paper has been presented at an IMF seminar and the conference on large-scale crises: 1929 vs 2008 . We thank the participants for comments.

${ }^{\dagger}$ Research Department, International Labor Organization, Geneva, Switzerland.

‡Dept. of Economics, New School for Social Research, New York, Bielefeld University, and ZEW Mannheim.

$\S$ Dept. of Economics, New School for Social Research, New York
} 


\section{Introduction}

The financial and economic meltdown and the large drop in output and employment after 2007-8 has created disinflation - and in some countries even a deflation - in a period with large debt overhang, invoking the Fisher debt deflation process of the 1930s. Yet, New Keynesian studies have found that neither the US nor the Euro-area has shown a collapse of the inflation rate despite the significant drop in output. Much research started to explain why the inflation rates moved down so slowly and have not been falling as much as expected. ${ }^{1}$ The process of disinflation and deflation in the Euro-area is slow. ${ }^{2}$ Yet, does the EU face a period of debt deflation and the risk of a protracted recession? Moreover, will a regime of financial instability re-emerge, exacerbating deflationary risks?

There are a few recent studies exploring such scenarios. The study by Werning (2011), adapting a shorter horizon, deals with those issues in terms of a liquidity crisis. He employs a linear quadratic macro model with central banks minimizing the loss from output and inflation gap, and shows for the linearized macro model with an output equation and Phillips curve that as inflation turns into dis-inflation, or deflation, the real interest rate tends to rise and the liquidity trap emerges, even if the interest rate is already at the zero bound. This occurs with slowly moving prices, as in the New Keynesian model, and becomes worse with fully flexible prices. Yet in this short-run model there is neither an evolution of debt nor a regime change in the financial market that could amplify the above process.

Another important recent study takes into account the evolution of debt and predicts a prolonged recession and a period of negative growth or slow growth in Europe, looking at debt build-up and debt overhang (see Krugman and Eggertsson $(2011)^{3}$ ). EK in their work refer back to the Fisher debt-deflation study of the 1930s and more generally to the Fisher-Minksy-Koo approach. In EK, a sudden deleveraging shock will lead to falling prices, thus increasing real debt which in turn will decrease spending, thereby amplifying the adverse effects on prices - generating the typical downward spiral of a debt deflation. Yet the overall deflationary process seems to be slow.

Regarding the evolution in the US and the Euro area one might not go so far as to invoke spiraling deflationary pressures, as the above two studies do, but what one obviously can observe is some debt overhang ${ }^{4}$ and a dis-inflationary process in most countries, with some Southern European countries even sliding into a deflation. At the same time there is still severe, and sporadically rising, financial market stress, in particular in some countries in Southern Europe. The issue is then whether there will be a dis-inflationary process that triggers a debt deflation spiral, and to what extent will it be magnified through a jump to high financial stress, high credit spreads, as well as strong adverse macroeconomic feedback loops, which all could contribute to generate a protracted period of recession. ${ }^{5}$

Another important issue is that the Euro-area is characterized by significant heterogeneity. This suggests that US type monetary and fiscal policies will not capture sufficiently the diversity in the Euro-area. A uniform monetary and financial market policy as well as growth and labor market policies may be limited in their effects. For example QE for the entire Euro-area might overlook the specific bottlenecks in credit flows, quantity constraints, and default risk areas. ${ }^{6}$

In the spirit of the above studies, and the need for permitting more heterogeneity in the EU, we introduce a dynamic macro model which allows for decentralized matching mechanisms on labor

\footnotetext{
${ }^{1}$ See Christiano et al. (2014).

${ }^{2}$ In the Great Depression the output level dropped from 1929 to 1932 by roughly $32 \%$ and the price level declined in the same time period by $22 \%$, see Marglin (2009), see also Fisher (1933). Though the drop in output in some Southern Euro-area countries was also high, prices dropped much less in the Euro-area since 2007-8, see figure 1.

${ }^{3}$ Some authors have discussed this also under the topic of a secular stagnation.

${ }^{4} \mathrm{~A}$ recent report by McKinsey (2015) seems to offer fresh evidence of this. Beside private and sovereign debt overhang, see Borio et al. (2015), there is also significant bank debt overhang, see Schleer et al. (2014)

${ }^{5}$ There is related literature that maintains that a prolonged recession could be a result of a deep financial shocks with strongly affected banking system Borio et al. (2015) or as a result of a hysteresis effects after episodes of long term underutiliztion of capacity and unemployment. For further causes of low growth and prolonged recessions, due to slowing innovations, Gordon (2016), excess savings, Summers (2014) and multiple policy issues, Lo and Rogoff (2015). Yet as mostly agreed the leading cause seems to be the debt overhang, see Lo and Rogoff (2015)), Jimeno (2015).

${ }^{6}$ See Brunnermeier and Sannikov (2014b).
} 
and financial markets, allowing for a more extensive analysis of heterogeneities across EU countries. Building on Ball and Mazumder (2014), and Gross and Semmler (2015), but similar to Werning (2011), we introduce a Phillips curve driving the rate of change of the inflation rate. Moreover, as in Krugman and Eggertsson (2011), we allow the build-up of debt to be impacted by the price level. On the other hand, financial market stress can accelerate contractionary forces, and can prevent recoveries from taking place, leading to a prolonged recession and unemployment. We show that there may be both dis-inflationary - or deflationary - and credit market mechanisms working to produce such effects. Those forces are possibly creating macroeconomic instabilities and regime changes. Since the EK model assumes nominal debt contracts, deflation itself, the Fisher effect, will be a contractionary force. On the other hand, if debt contracts are in real terms, or represent inflation-adjusted one-period debt, the contractionary debt deflation effect might be reduced. ${ }^{7}$ Yet, the financial market contraction may still be amplifying.

The forces resulting from a debt-overhang and disinflation/deflation are working through the product and asset price dynamics and then through credit channels. In our model, there is leveraged investment and borrowing by households from the credit market, mediated through financial intermediaries, as well as bond issuing. Contracting credit markets and higher credit spreads caused by previous excess leveraging and higher cost of borrowing - can create severe macro feedback effects and regime changes and financial market stress, so that households and firms also face credit constraints and rising credit spreads, such that overall aggregate demand tends to fall. ${ }^{8}$

When aggregate demand falls, households, firms and banks can default, which in turn create greater financial market stress, larger credit spreads, lower aggregate demand and so on. At the same time, on the price side, one can observe some disinflation or worse, deflation, affecting the above dynamics. Even though the nominal interest rate may be at a lower bound, if there is disinflation the real interest rate rises. If aggregate monetary policy cannot manage to generate a declining or negative real interest rate by increasing inflation, then a lower bound - possibly the zero-lower bound - of the interest rate binds, output stays low and unemployment rises.

Debt deflation and financial market risk drivers accelerate downturns, possibly creating lockins into a prolonged period of a recession. This is basically working as positive feedback loops between the product market, price dynamics, credit and financial market and economic activity, ${ }^{9}$ where there might be excess savings, accompanied by a long lasting recession and unemployment, or even a secular stagnation, as Summers (2014) and others have predicted. In this sense it is not a deleveraging shock but rather a slow process of debt-disinflation or debt-deflation, accompanied by rising financial market stress and credit spreads, that is causing the long-lasting recession. This way monetary policy faces great challenges and might not be effective on the aggregate level.

Our matching mechanisms on the labor market follows Merz (1995) and Ernst and Semmler (2010). The matching mechanism on the credit market is handled through financial intermediation mechanisms, similar to Wasmer and Weil (2004) and Cui and Radde (2014). Both mechanisms potentially allow for heterogeneity and can be employed to study the financial macro linkages in a multi-period model. We do this without building on an infinite horizon model of the macroeconomy, where agents usually have rational expectations and smooth consumption in the infinite horizon context, and experience preference, technology and policy shocks, yet regime changes do not occur. Usually in this context, models are linearized and only small deviations from the steady state are allowed for, and large shocks are difficult to account for. ${ }^{10}$

In contrast, our approach permits to study the credit-macro feedback mechanisms in a multiperiod model without assuming an infinite time decision horizon. As to the solution method, our model will not be solved locally through local linearization around the steady state, as used in DYNARE, or globally by Dynamic Programming, as in Ernst and Semmler (2010), but by nonlinear model predictive control (NMPC), which has recently been developed by Gruene and Pannek

\footnotetext{
${ }^{7}$ This has been an argument against the Krugman and Eggertsson (2011) model.

${ }^{8}$ See Blanchard and Leigh (2013). Those positive feedback loops are already mentioned in Fisher (1933).

${ }^{9}$ This naturally shows up in some measures of capacity utilization. Many recent DSGE models have started working with endogenous capital utilization and financial market, for example cost of capital when issuing bonds. A relationship between capital utilization and the "user cost of capital" is also postulated by Keynes (1936).

${ }^{10}$ The models by Werning (2011) and also Krugman and Eggertsson (2011) are also infinite horizon models and solved through local linearizations.
} 
(2011) and applied in Gruene et al. (2015). This numerical method allows for approximating the accurate dynamics of the model by an N-period receding horizon model which will provide us with an approximate solution for the decision and state variables. Though the NMPC numerical method approximates the infinite time horizon model, with time periods $N$ becoming very large, the NMPC permits one to explore important issues, such as the rise of important constraints and regime switching, in a model with a shorter time horizon.

In the empirical part we explore the impact of policy effects in typical regimes, such as booms and recessions. We then take the model to the data and estimate and apply a multi-regime VAR (MRVAR), as used Mittnik and Semmler (2013)), and Schleer and Semmler (2015), and Schleer et al. (2014). ${ }^{11}$ But since we want to study also deflationary risk drivers, in addition to financial risk drivers, our MRVAR employed here is higher dimensional and the MRVAR and the IRFs work with four important macro variables such as output, inflation rate, credit spread and financial stress.

The remainder of the paper is as follows. The next section presents some stylized facts concerning debt-deflation dynamics and considers the differences between different world regions. Section 3 presents the theoretical model with decentralized labor and credit market matching mechanisms, that introduces inflation and the dynamics of the price level and their impact on the capital stock, leveraging, output gap and employment. Section 4 studies the financial risk drivers in a model with endogenous regime change in the finance-macro link. In section 5 the higher dimensional MRVAR methodology is applied to detect nonlinearities and regime changes in the link between output, inflation rate, credit spread and financial stress. The IRFs for shocks on those variables are explored in an econometric regime-change model. Some policy conclusions are drawn in section 6. A final section concludes. Technical details and some explorations of regime dependent macro laws can be found in the appendix.

\section{Stylized facts and GVAR results}

Stylized facts of the Euro-area demonstrate the precarious deflationary trends in the EU as compared to other regions of the world such as the US and Japan. This can be shown making use of a large-scale Global Vector Autoregression model (GVAR) developed by Cesa-Bianchi et al. (2014) and applied in Binder and Gross (2013).

Let us first establish to what extent there has been disinflation or even deflationary pressures in the EU. Figure 1 demonstrates that deflation is particularly prevalent in the Southern countries (Italy, Spain, Portugal and Greece). In contrast, Northern countries (Germany, France, Austria) only show disinflation. Nevertheless, despite the sharp rise of unemployment among Southern European countries, the drop in inflation remains relatively modest, an issue we will explore below.

\footnotetext{
${ }^{11}$ We can allow for regime switching, as can be found in recent DSGE models, see Schorfheide (2005) and Farmer et al. (2009). There, however, it is assumed that the Euler equation, based on an infinite horizon solution, holds.
} 
Figure 1: Unemployment and inflation during the crisis: EU North vs. EU South

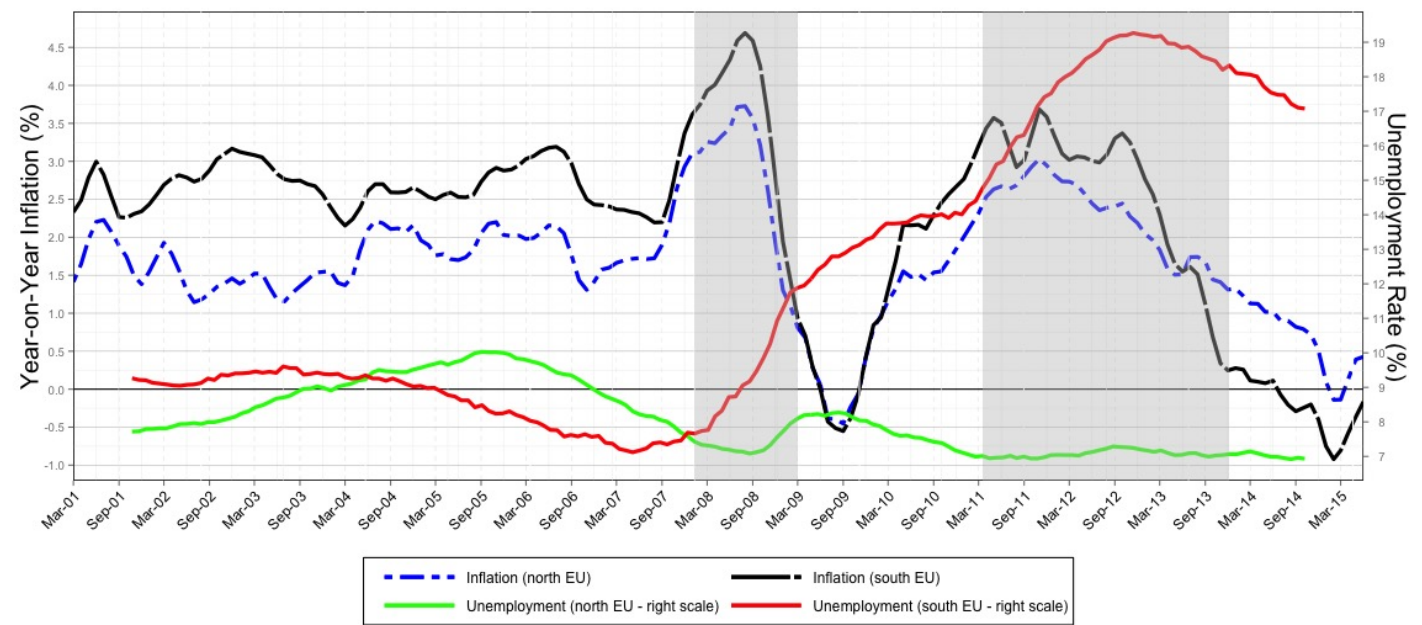

Using the GVAR methodology put forward by Binder and Gross (2013) allows to explore the relative importance of the deflationary mechanism for the EU, Japan, US and United Kingdom. GVAR allows for a large scale econometric approach to model the economic interdependence in macro variables not only for time series data but also permits to model the interdependencies across countries. Using trade-weights, the interlinkages between countries can be studied by combining a set of country-specific VARs that contain weighted foreign variable vectors. This approach permits to model simultaneously a large number of countries, and a broad set of economic time series variables in one model. Usually, modelling an unrestricted conventional VAR is not feasible due to the large number of parameters. The GVAR shows how one can set up and use multiple crosssections, while, at the same time, studying time series data of countries and regions. In our set-up, we use the inflation rates, GDP growth, equity market performance, short and long term interest rates, raw material and oil prices and exchange rates. ${ }^{12}$

The results of the GVAR study show that the EU has recently revealed stronger deflationary trends than the US, UK, and Japan. In many EU countries there is not only disinflation, but there is also deflation and a threat of a deflationary spiral. The impact on output, inflation rates and interest rate is studied with the GVAR model using a large macro data set for the EU, US, UK, and Japan. ${ }^{13}$

Figure 2: GVAR results - Deflation shock on GDP

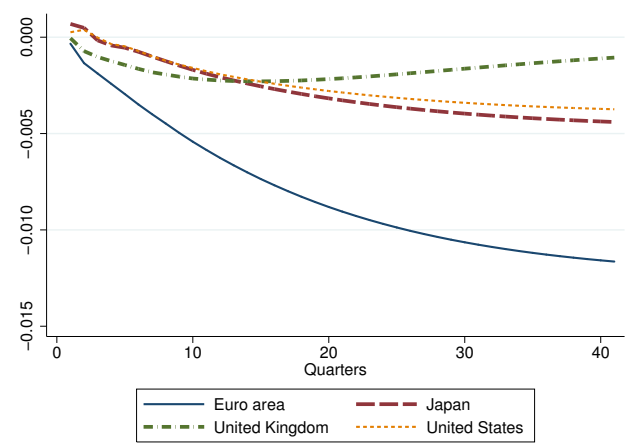

\footnotetext{
${ }^{12}$ Data on those variables can directly obtain within the GVAR program.

${ }^{13}$ For the data set, see Binder and Gross (2013).
} 
Figure 2 shows the response of GDP to a deflationary shock in the Euro area, UK, Japan, and the US. It reveals that there is a much stronger deflationary pressure in the EU than in Japan, US and United Kingdom. Though many economists thought that Japan went through a period of deflationary pressure, it seems to look even more severe for the EU now.

\section{Vulnerability through debt-deflation}

The basic model that serves as a starting point for our theoretical considerations is described in appendix 2 . In this section, we want to start by introducing the inflation rate and price level effects into our macro dynamics with leveraging. In the next section, we will introduce financial market reactions, and macro feedback loops, resulting from higher leveraging of the agents in the economy.

As mentioned, after the Great Recession researchers where wondering why the inflation rate did not quickly drop but moved down only very moderately. This is in contrast to the Great Depression, where the price level dropped by roughly 25 percent. ${ }^{14}$ To understand the slowly moving debt-deflation risk drivers, we introduce inflation and price level dynamics into our basic model.

\subsection{A model with debt dynamics and inflation}

We follow the recent literature on slow inflation dynamics by letting the change of the inflation rate be driven by a slightly modified new type of a Phillips curve, such as in Werning (2011) and in Gross and Semmler (2015). We augment the basic model of appendix 2 with inflation and price level dynamics and incorporate their impact on the evolution of debt. The augmented core model then reads as follows:

$$
\max _{C_{t}, \mathcal{I}_{t}, \mathcal{V}_{t}} \int_{0}^{N} U\left(C_{t}, N_{t}\right) e^{-\rho t}=\int_{0}^{N}\left\{\frac{C_{t}^{1-\eta}}{1-\eta}-e N_{t}^{\chi}\right\} e^{-\rho t}
$$

s.t.

$$
\begin{gathered}
\dot{N}_{t}=m^{L}\left(s_{t} \cdot \mathcal{U}_{t}, \mathcal{V}_{t}\right)-\sigma N_{t} \\
\dot{K}_{t}=m^{B}\left(\mathcal{I}_{t} / P_{t}, \mathcal{B}_{t} / P_{t}\right)-\delta K_{t} \\
\dot{d}_{t}=r d_{t}-\frac{1}{P_{t}}\left(v\left[P_{t} Y_{t}\left(K_{t}, A N_{t}\right)-P_{t} C_{t}-P_{t} I_{t}-\Phi\left(s_{t}\right)\left(1-N_{t}\right)-\zeta \cdot \mathcal{V}_{t}-\phi\left(g_{t} K_{t}\right)\right]\right)-\pi_{t} d_{t}
\end{gathered}
$$

Here, $C_{t}$ represents aggregate consumption, $Y_{t}$ : aggregate production, $A$ : (exogenous) labor productivity, $\mathcal{F}_{t}$ : available financial funds through savings and external borrowing, $\mathcal{B}_{t}=\mathcal{F}_{t}-C_{t}$ : offered bonds to firms, $r$ : the nominal interest rate, $N_{t}$ : employment, $\mathcal{V}_{t}$ : vacancies and $\phi\left(g_{t} K_{t}\right)$ represent adjustment cost and bond issuing cost. In addition to costly search on the labor market, issuing bonds adds another cost factor to the macroeconomic resource constraint, with per-period flow costs $\phi\left(g_{t} K_{t}\right)$, representing bond issuing and adjustment costs. The preferences are over consumption flows, $C_{t}$, and employment, $N_{t}$.

The dynamics of eq. (1) represent the evolution of employment with the labour force normalized to one. Eq. (2) denotes the evolution of the capital stock and eq. (3) represents the dynamics of aggregate debt in real terms (for both households and firms). ${ }^{15}$ Our debt dynamics is written in a standard way if one allows for borrowing of the private (or public), possibly also from abroad. ${ }^{16}$ Moreover, we have deflated the nominal variables - including the debt level - by the price level $P_{t}$, and we have to add the term $\pi_{t} d_{t}$ with $\pi_{t}$ the inflation rate. ${ }^{17}$

In eq. 3 , the term [.] represents external borrowing $(>0)$ or repayment $(<0)$, in the former case used for excess spending over domestic income. Moreover, we assume $\mathcal{F}_{t}=\mu C_{t}, \mu>1$.

\footnotetext{
${ }^{14}$ For the price level fall, see Marglin (2009), and for the impact of price level fall and income fall on credit risk and bank defaults, see Bernanke (1983), but also Fisher (1933).

${ }^{15}$ We could also allow for sovereign debt here, though we do not specify what fraction of debt is driven by households, firms or the public sector.

${ }^{16}$ see Blanchard and Fisher (1989, ch.2) and Blanchard (1983).

${ }^{17}$ We hereby assume that the capital stock in (2) is already deflated.
} 
Thus, consumption can be smoothed intertemporally, but investment funds might be restricted. This means investment is more scrutinized through decentralized financial market matching mechanisms, ${ }^{18}$ but if there is a consumption boom, more investment funds will also be available on the credit market. ${ }^{19}$

Moreover, search costs, $\Phi(s)$, are assumed to be fixed, with constant search effort $s=0.2$. The function $m^{L}\left(s \cdot \mathcal{U}_{t}, \mathcal{V}_{t}\right)$ in eq. (1) represents a decentralized matching function on the labor market. Given the decentralized matching process $m^{L}\left(s \cdot \mathcal{U}_{t}, \mathcal{V}_{t}\right)$ the job finding rate of the unemployed will be $m^{L}\left(s_{t} \cdot \mathcal{U}_{t}, \mathcal{V}_{t}\right) / \mathcal{U}_{t}$ which - assuming constant search intensity - will depend on the vacancies posted by firms and the unemployment rate. ${ }^{20}$ The job finding rate is thus the ratio of the numbers of new hires divided by the number of workers searching for jobs. With higher unemployment and lower vacancies the job finding rate is lower. ${ }^{21}$

On the credit market there is also a decentralized matching mechanisms, defined by $m^{B}\left(\mathcal{I}_{t}, \mathcal{B}_{t}\right)$, which represents the decentralized matching mechanisms for the credit market. Both matching functions for labor and credit markets display constant returns to scale and are represented by a Cobb-Douglas functions with exponents $q_{0}=0.5$ and $q_{1}=0.5$. The parameters $\sigma, \delta$ are the separation rate and depreciation rate of capital, and $v$ is our regime switching parameter which will be either 1 or 0 , depending on the degree of leverage permitted in the economy.

Partly because of recent empirical evidence and partly to avoid modelling the supply of funds, we have made the supply of funds for firms' investments a function of the supply of funds $\mathcal{F}_{t}-C_{t}$. Given the external funding and the consumption decision, a fraction of funds can be used for providing bond offering to be matched with the demand for bonds arising from firms' desired investment $\mathcal{I}_{t}$. Funding for consumption will be available from domestic and external sources, but investment funding will be obtained on the credit market by the decentralized matching process on the credit market.

As in the basic model we assume that consumption is a direct decision variable and investment is expressed as intended investment, $\mathcal{I}$, to be matched with the supply of bonds, given by $\mathcal{F}_{t}-C_{t}$. This assumption allows us to work with a lower dimensional system. It also could be interpreted that the screening and monitoring of investment funding takes place more extensively than funding for smoothing consumption. In the context here, consumption is only indirectly constrained, namely through the state variables and the dominant component of demand as the IMF (2015) study seems to suggest.

Finally, we have to formulate how we obtain the inflation rate and construct the price level $P_{t}$. Similar to some New Keynesian literature we assume that inflation rate and the price level adjust slowly. ${ }^{22}$ As in the NK view we can then proxy the inflation dynamics by the output gap and a proxy for an expected inflation rate. Here, however, we are working with the rate of change of the inflation rate.

$$
\dot{\pi}_{t}=\beta\left(\frac{Y_{t}}{Y^{*}}-1\right)+\eta^{c}{ }_{t}
$$

We let the change of the inflation rate respond to the output gap and some expectation term. Using eq. (4) we rely on demand and cost pressure arguments but because of numerical reasons we have chosen a short-cut of the Phillips curve. The inflation adjustment eq. $(4)^{23}$ follows

\footnotetext{
${ }^{18}$ In principle, this allows us to study more properly the heterogeneity of the euro area credit market.

${ }^{19}$ This, for example, was likely to be the situation in Spain before the financial meltdown of the years 2007-9. Of course, there are likely to be constraints for households' borrowing as well, which will be discussed in section 4 . For a more general empirical result on the dominance of household behavior on borrowing and a sluggish response of investment demand, see IMF (2015).

${ }^{20}$ This gives rise to the usual Beveridge curve.

${ }^{21}$ For details, including also time varying labor market participation rates, see Christiano et al. (2014).

${ }^{22}$ Usually the Calvo price setting procedure or the Mankiw quadratic adjustment cost of prices are employed to get sticky prices. Our subsequent formulation is not inconsistent with views that presume that prices are driven by marginal cost and expected inflation rates, see Keen and Wang (2007). There is then shown that through a linearization the usual Phillips curve relationship is then proxied through a local output gap and expected inflation rate.

${ }^{23}$ Flaschel et al. (2007) write the inflation rate being determined by $\pi=\beta_{u}\left(u^{*}-u\right)+\beta_{Y}\left(\frac{Y}{Y^{*}}-1\right)+\kappa \pi^{c}$;
} 
in principle Rudebusch and Svensson (2002) as employed in Werning (2011). ${ }^{24}$ In RS, however, inflation responds in a discrete time manner to time lags of the endogenous variables, to the output gap and a moving average of inflation rate, with the latter term proxying expected inflation. In our case, we have formulated a model corresponding to Rudebusch and Svensson, but written in continuous time, using the rate of inflation as a differential equation. Note that starting with the derivative of the inflation rate might make sense, since the inflation rate does not jump and in many EU countries still tends to be slightly positive though the change of the inflation rate itself was negative for a long time and now the inflation rate slowly turns to be negative too.

The inflation rate expression, $\eta^{c}{ }_{t}$, represents the inflationary climate - of the change in inflation rates - in which the current inflation dynamics is operating. The climate variable $\eta^{c}{ }_{t}$, is thus a magnitude that is related to the medium run and can be viewed to be updated in an adaptive fashion, as explained in the footnote for eq. (4). Our inflation climate variable is constructed in a similar way as in Ball and Mazumder (2014) who introduce some smooth process of inflation expectations by anchoring the inflation expectations in survey data.

Note that our inflation dynamics could be interpreted as based on cost push pressures and demand pressures ${ }^{25}$ affected by the output gap and thus capacity utilization. Note also that in eq. (4) we only use goods' price inflation and thus assume that wage and price inflation do not differ much when averaged over the medium-run. Wage cost pressure that firms are facing could be formulated in a second term. For a detailed analysis of the stability properties of such price and wage Phillips curves, see Flaschel et al. (2007). Empirical evidence on slowly moving inflation rates, justifying to focus on the change of inflation rate, as in eq. (4) is given in Gross and Semmler (2015) and in appendix 5, where a regime dependent Phillips curve is studied.

An important reason why there is disinflation rather than deflation - or the inflation does not become strongly negative as much research recently has pointed out - is that during contractions, such as the recent one, the demand pressure will reduce prices but the risk premia and credit spreads increase credit costs, in particular for credit on working capital, pushing up costs. ${ }^{26}$ So there is a cost push as well as a demand effect working, preventing the inflation rate from falling less than one would expect.

Lastly we need to introduce the aggregate price level dynamics, since this is used in eqs. (2)-(3). The price level dynamics can be defined through the following differential equation:

$$
\dot{P}_{t}=\pi_{t}
$$

Note that eq. (5) can be used to determine a price index, starting with $P_{0}=1$, that represents the integrated inflation rates as a solution of eq. (5), so as to obtain $P_{t}$.

The following parameters for the NMPC solutions are used: $\mu=1.3$ and $\beta=035, \kappa=0.1$, $\rho=r=0.03, \delta=0.03, \sigma=0.04, \alpha=0.36, A=1, \xi=0.07, \chi=5, e=1$. The parameter $v$ is set to one, which means there are no credit constraints (if set to zero there are credit constraints). In our numerical solution algorithm we start with a price level $P_{0}=1$, integrate the inflation rates following eq. (5) to obtain $P_{t}$ and deflate appropriately the nominal variables such as the demand for firms' funds and the bond supply, $\mathcal{I}_{t} / P_{t}, \mathcal{B}_{t} / P_{t}$, in eq.(2). We also deflate debt service in eq.

with $\dot{\pi}^{c}=\beta_{\pi^{c}}\left(\pi-\pi^{c}\right)$. In the first equation, the first term on the right hand side defines the unemployment gap (representing pressure from the labor market) and the second the output gap (representing pressure from the product market), see Flaschel et al. (2007)). The second equation, a differential equation, defines an expectational term, the inflation climate, with a path toward a steady state inflation rate. The expectational term represents the change of the climate inflation and can be interpreted as in Ball and Mazumder (2014) as an anchor of inflation rates, as a consensus forecast of CPI inflation or as inflation climate, similar to Flaschel et al. (2007), see also Gross and Semmler (2015) and their use of survey data. In our eq. 4 we have only used the first term of the inflation dynamics $\pi_{t}$, and we have set $\eta_{t}^{c}=\dot{\pi}^{c}$. In our subsequent numerical solutions we use eq. 4 for an inflation dynamics, and thus employ only the output gap and let the dynamics of $\dot{\pi}^{c}$, being generated by some moving average of the change of inflation rates.

${ }^{24}$ Werning (2011), however assumes a form where the current change of the inflation rate is anchored in the purely forward looking form of the agents' behavior, and thus he has a negative sign for the output gap. Econometric evidence for this formulation seems to be very weak as Gordon (2011) and Ball and Mazumder (2014) argue. This criticism does not hold for Rudebusch and Svensson (2002). We follow more the latter approach.

${ }^{25}$ see also Christiano et al. (2014).

${ }^{26}$ For details, see Christiano et al. (2014) 


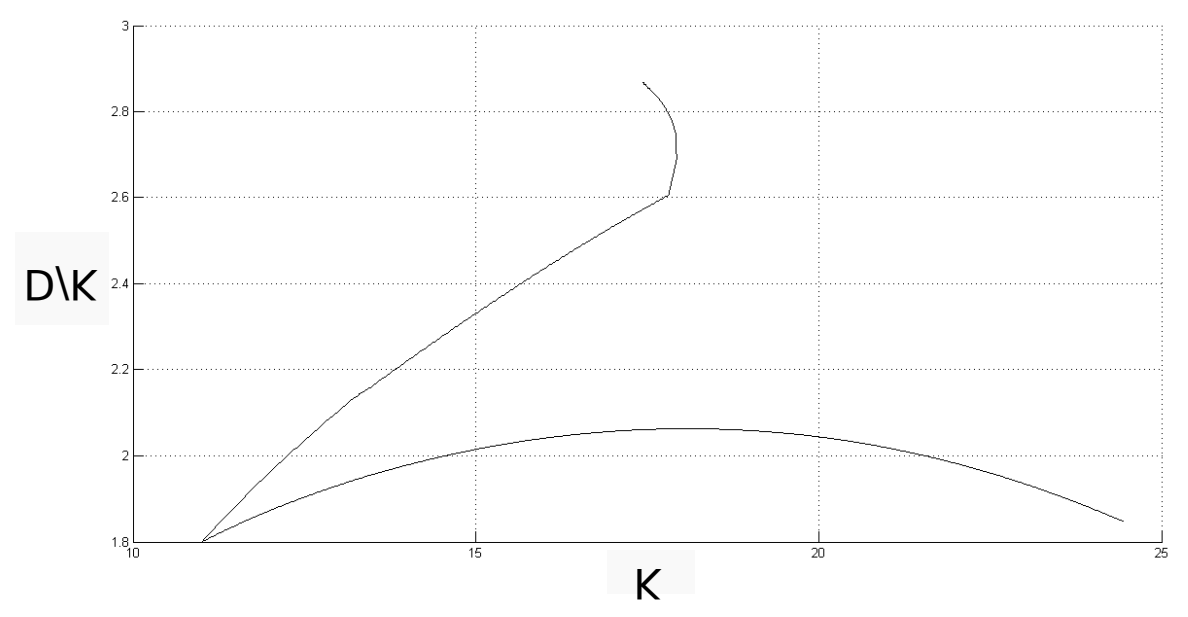

Figure 3: Solution path of capital and real debt to capital ratio; initial condition for $N(0)=0.9$ and $D(0) / K(0)=1.8$, lower trajectory: because of low and declining real interest rate, $K_{t}$ moves up and the leveraging ratio moves up a bit and then down; upper trajectory: because of deflation and high real interest rates, and high debt, $K_{t}$ first moves up, but then down, and debt and the leverage ratio become unstable

(3), income, total financial funds, the search cost for jobs as well as the search cost for issuing bonds. This way we obtain the evolution of the variables in real terms, and also debt in real terms, as determined by the level of debt, the excess of income over spending and the interest rate and inflation rate.

We solve this higher dimensional macro model (1) - (5), that makes the debt-deflation risk drivers explicit, by using NMPC with the above defined objective function for a finite time horizon. In our numerical solution we start now in the vicinity of the steady state of the basic model - but in order to proxy a recession, we also start with a negative output and employment gap. We take $N(0)=0.9$ as the initial employment rate. ${ }^{27}$ We track the path of all state variables, including the inflation and price dynamics as defined in eqs. (4) and (5).

In the numerical solution of the model (1)- (5) we can distinguish two cases (as depicted figure 3). The upper trajectory represents one case, the lower trajectory another case. As our price adjustment process suggests sticky prices, we have slow inflation rate movements. Moreover, we assume that when the economy contracts we have different initial conditions for the price adjustment process. How do those two cases emerge in figure 3? This will be discussed next.

\subsection{Debt deflation and slow recovery}

The lower trajectory of figure 3 presumes that we start with an economy that had not experienced disinflation, the inflation rate is at target, roughly 2 percent, we thus commence with an initial $\pi(0)=0.02$. Yet, the fiscal or monetary policy may have initiated a slight recovery, and the output gap starts closing again. Given a nominal interest rate of $r=0.03,{ }^{28}$ we can observe that the ratio of real debt to capital stock first rises but then declines after a while. The latter is due to low interest rates, excess of income over spending, positive inflation rates, and a rising price level, arising from eq. (4), and thus declining real interest rates. As we can observe from figure 4 and

\footnotetext{
${ }^{27}$ In our model, there is no labor force inactivity, so the employment rate is simply the inverse of the unemployment rate.

${ }^{28}$ Note that in this section we keep the nominal interest rate on a fixed level, but of course the central bank may reduce the interest rate to the lowest bound possible. On the other hand, market credit cost may still be higher due to credit spreads. To capture this effect we keep a constant interest rate, this will be changed in sect. 4 .
} 
5 the inflation rate goes up to almost $\pi_{t}=0.045$ and the employment gap, figure 5 , declines (and the output gap declines as well, not shown here). ${ }^{29}$

Note that we have imposed an initial inflation rate of $\pi(0)=0.02$, which was roughly the inflation target of the central banks, at the beginning of the Great Recession. We start with this target, even if the economy moves into a recession with a negative output gap. Yet, prices are sticky downwards. There is a positive inflation rate, but it is first slightly decreasing, see figure 4, so the inflation rate first moves slightly down with excess capacity and a negative employment gap, both representing downward demand pressures, but then rises again. This may in fact represent some of the countries' experience when there was no self-enforcing debt deflation or disinflation, for example the US, and the UK, but also Germany, and France, where inflation rates have not fallen much.

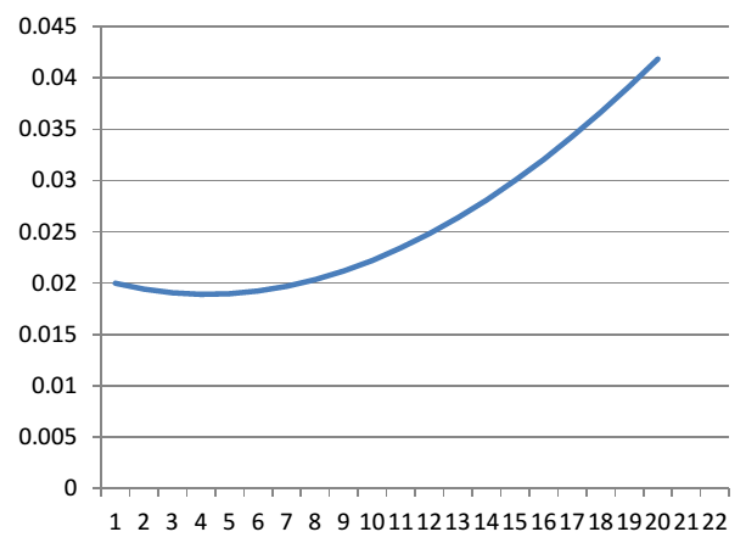

Figure 4: Inflation rate corresponding to lower trajectory of figure 3; starting with negative employment gap, first slightly declining inflation rate, then inflation rate rising with diminishing employment gap, for initial $\pi(0)=0.02$

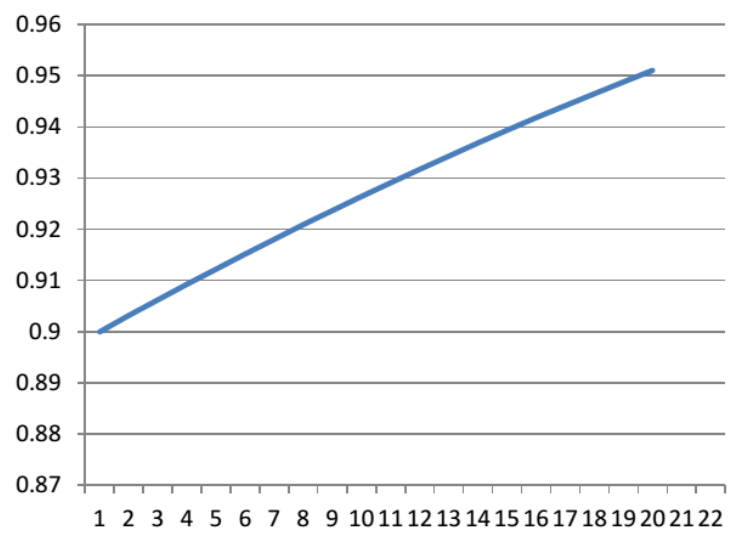

Figure 5: Employment gap corresponding to lower trajectory of figure 3; diminishing employment gap over time, for initial values $\pi(0)=0.02$

\footnotetext{
${ }^{29}$ It is interesting to observe the employment gap and inflation rate. They are both driven by the output gap which is endogenously given from the system (1)-(5) not depicted here. Figures 4 and 5 represent the inflation path given by eq. (4) and the employment gap path respectively. As shown, the inflation rate is rather sticky and does not turn negative even with a negative employment gap, see figure 4, but moves only down little when there is an employment (output) gap. We thus can observe disinflation with such a gap, but not necessarily a deflationary process.
} 
The main effect of the path toward sustainable debt comes from the growth or income term in eq. (3). The credit cost is almost cancelled out by the inflation rate and if there is sufficient income growth the term $v[$.$] may have a positive sign, allowing the economy to grow out of debt.$ So, output and income growth also allows the output gap to close, pushing up the inflation rate (see figure 4 where the inflation rate is moving up to $4.5 \%$, reducing even more and more the real cost of borrowing). ${ }^{30}$

\subsection{Debt deflation and prolonged recession}

Things change when initial inflation conditions are much lower. Let us consider the initial inflation rate being much lower, triggered by a negative output gap. We assume that the central bank cannot - or is not willing - to generate lower interest rates fast enough and cannot cause inflation rates to move up. Since the inflation rate is sticky through eq. (4), even if there is a slight recovery, the inflation rate is only rising slowly with declining output and employment gaps.

In figure 3, the upper trajectory shows the path of the real debt-to-capital ratio when we start with an economy that had experienced disinflation and the actual inflation rate has become zero, or negative. We start with an initial $\pi(0)=0$, but, because of high real real interest rates (nominal interest rate is 0.03 and inflation rate zero), the slightly rising inflation rate reduces the nominal interest rate only very little - and the high debt level moves up further. The last term in eq. (3) is very small as compared to the first term, and if the middle term does not move much, because output and income does not grow, debt will rise. ${ }^{31}$ We can observe here that the debt and leverage ratio eventually becomes unstable, though the capital stock, $K_{t}$ first moves up, and declines afterwards. ${ }^{32}$ The main effect on the rise of debt comes from both, the rise of the real interest rate and the slow or negative income growth. ${ }^{33}$

Figure 6 is for the upper trajectory of figure 3, depicting the path of the inflation rate. Figure 7 shows the same closing of the employment gap, driven by the closing output gap. But note that all of this still holds if we stay in a regime with little financial stress, with no rise in credit spreads, but below the steady state variable of $N_{t}<N^{*}$ and $Y_{t}<Y^{*}$ (see figure 7 for the employment gap). This may in fact represent some EU countries experience when there was self-enforcing debt deflation or disinflation, for example Greece, Portugal, and Spain, and also Italy recently, where inflation rates moved down to zero and even below zero, letting real interest rates rise. ${ }^{34}$

Though in both cases, the upper and lower trajectory in figure 3, the economy may recover but in the case of the lower trajectory, the economy recovers more quickly whereas for the upper trajectory, with only slowly moving inflation, rising real interest rate and possibly rising debt burden, there is further increase of debt overhang and the economy is possibly moving into a slow moving debt crisis to be discussed further in sect. 4 .

Note that in figures 4 to 7 the corresponding output and employment gaps, and thus the inflation rate, are driven by the system (1)-(5). In our simulations a normal level of employment is set at $95 \%$ of the available labor force. We have normalized this to 1 in figures 5 and 7 . The employment level, given the large output gap we start with, is low and thus unemployment is high, roughly about 10 percent, as one could observe after 2007-8 in most countries. But also note that the employment gap is endogenously generated, and it is also a result of the vacancy rates chosen by firms, given the dynamic model (1)-(5).

So far we have presumed no further financial market reactions and financial market stress, and we have not taken into account a possible regime change on the financial market, with rising default risk and credit spreads, and possibly adverse macro feedback loops. One is likely to expect different outcomes with such a rising financial market stress. We will explore some important

\footnotetext{
${ }^{30}$ This is what Tobin (1987) had in mind when discussing debt sustainability. Note that this is also consistent with the debt sustainability defined by Bohn (2007).

${ }^{31}$ This is an argument used in the study of sustainable debt already by Tobin (1987). This maybe amplified if financial stress jumps up.

${ }^{32}$ If recently the inflation rate was falling further, it was presumably due to the decrease in the oil price.

${ }^{33}$ This again can be illustrated by using the Tobin debt sustainability model, see also Fisher (1933).

${ }^{34}$ But note if the bonds and thus the debt are partially indexed, one would get a weaker effect, as will be discussed in section 4
} 


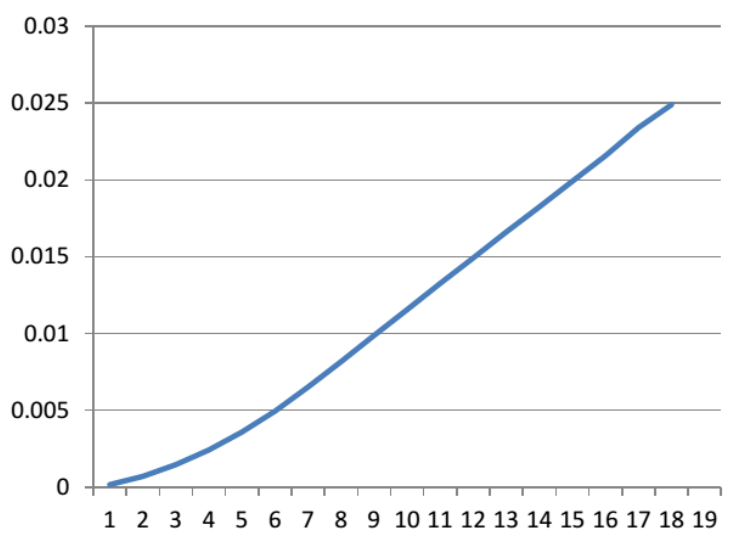

Figure 6: Inflation rate corresponding to upper trajectory of figure 3, starting with a zero initial inflation rate, triggered by a negative output gap; inflation rate is only slowly rising with declining output and employment gaps, initial inflation rate $\pi(0)=0.0$

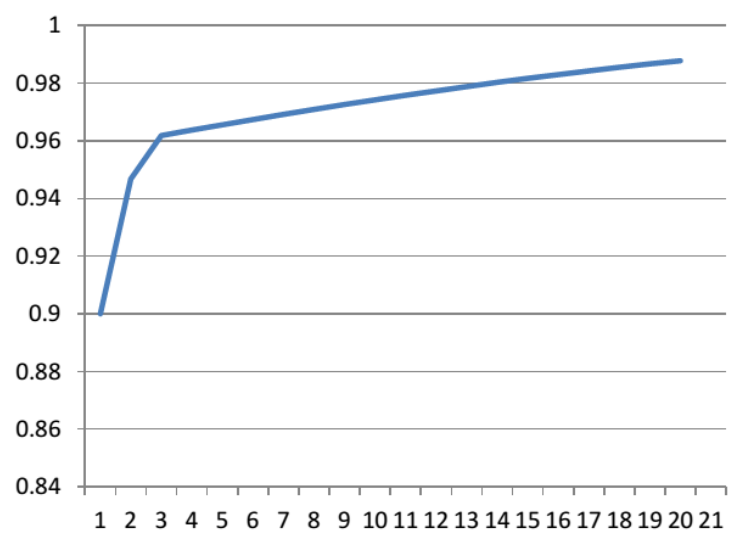

Figure 7: Employment gap corresponding to upper trajectory of figure 3; first faster then slowly declining employment gap 
empirical features next and other aspects in appendix 5 .

\section{Financial market instability and regime change}

We want to allow now for a rise of financial market stress, possibly due to rise of unsustainable real debt (of households, firms banks, sovereign), resulting in higher default risk, risk premia and credit spread and thus in a contraction of credit flows.

We will thus introduce an endogenous rise of risk premia and credit spreads to become strong factors in the macro dynamics which also trigger credit cost to go beyond the deflation risk drivers discussed in the previous section. To study this issue we can set the price index $P=1$ and thus $\pi=0$, for all $t$. Since we want to consider other major contractionary financial forces now, the Fisher debt-deflation effect is neglected in the next step. This also could be seen as roughly equivalent to fully indexed bonds and thus debt. ${ }^{35}$

We again refer back to the basic model of appendix 2, but now we will introduce endogenous credit cost and and credit spreads. We explore two model variants. In one version there are only very weak macro feedback effects to aggregate demand when credit spread is rising. In the other version we will include stronger macro feedback effects. This modeling strategy is important because it brings out the role of leveraging, debt overhang, financial instability and credit cost jumps which are not present in the liquidity model such as Werning (2011).

\subsection{Endogenous credit spreads and weak macro feedbacks}

Our model with endogenous risk premia and credit spreads ${ }^{36}$ can be written as follows.

$$
\begin{aligned}
& \qquad \max _{C_{t}, I_{t}, \mathcal{V}_{t}} \int_{0}^{N} e^{-r t} U\left(C_{t}, N_{t}\right) d t \\
& \text { s.t. } \\
& \dot{N}_{t}=m^{L}\left(s U_{t}, \mathcal{V}_{t}\right)-\sigma N_{t} \\
& \dot{K}_{t}=m^{B}\left(\mathcal{I}_{t}, \mathcal{B}_{t}\right)-\delta K_{t} \\
& \dot{D}_{t}=r\left(f s_{t} \mid \gamma,\right) D_{t}-v\left[Y_{t}-C_{t}-I_{t}-\Phi\left(s_{t}\right)\left(1-N_{t}\right)-\zeta \cdot \mathcal{V}_{t}-\varphi\left(g_{t} K_{t}\right)\right]
\end{aligned}
$$

In eq. (6) there are again preferences over log utility and non-working time. The policy variables are consumption, growth rate of capital stock, and vacancies posted by firms, $C_{t}, g_{t}, \mathcal{V}_{t} .{ }^{37}$ As before, eq. (7) represents the decentralized matching mechanism on the labor market and credit market and we continue to assume the search effort $s$ to be constant. The capital stock increases due to investment financed via the decentralized search and matching on the credit market (see eq. (8)) and declines with capital depreciation at rate $\delta$. The interest payment on debt, $r(\cdot) D_{t}$, now increases with debt but the surplus $v\left[Y_{t}-C_{t}-I_{t}-g_{t} K_{t} \ldots ..\right]$ - negative excess absorption decreases debt. Hereby again we have set $I_{t}=g_{t} K_{t}$. The interest rate is now driven by financial stress, $f s_{t}$, as discussed above.

The expression in brackets $v[\cdot]$ can be interpreted again as change in external liabilities. As before, since consumption and investment are separate policy variables we allow for external borrowing. As before, $\varphi\left(g_{t} k_{t}\right)$ is a quadratic adjustment cost for investment, included in eq. (9). Overall the model has now three decision variables and three state variables. ${ }^{38}$

\footnotetext{
${ }^{35}$ This might avoid the criticism of the EK model of assuming not having indexed bonds.

${ }^{36}$ Blanchard (2013) expresses this as a jump to a second, bad, equilibrium: "The higher the debt, the higher the probability of default, the higher the spread on government bonds, and the harder it is for the government to achieve debt sustainability. But the adverse effects do not stop there... ".

${ }^{37}$ Actually in the numerics we can take $c_{t}=C_{t} / k_{t}$, so that the first two choice variables can be confined to reasonable constraints between 0 and 1 .

${ }^{38}$ Note that we assume here a difference of interest and discount rates. Krugman and Eggertsson (2011), and also Brunnermeier and Sannikov (2014a), give a justification of why the interest rate might be different from the discount rate.
} 
Arellano (2008) argues that, with a probability of default, the market price to be paid for the next period's bond is affected. If the bond actually defaults the value of the bond is zero and there is a welfare loss for the bond issuer. ${ }^{39}$ If the bond issuer is not defaulting the bond continues to be in use and the bond price (inversely the yield) will fall due to the level of debt and rise due to a positive shock on income. Now one can think of those two extreme scenarios as off-on cases. ${ }^{40}$ If we want to smooth out the off-on cases, as the only two scenarios, we can perceive a continuum of cases where the probability of default may steadily rise starting from a low level, and then leveling off, where no bonds can be be issued any more. One can make the bond prices and thus the yields, a nonlinear function of financial stress arising from leveraging and default risk. ${ }^{41}$

Iin contrast to the model variant of section 3, therefore, here we assume that the actual interest payments are a nonlinear function of some measure of leveraging. Hence, we represent $\left.r\left(f s_{t} \mid \gamma, c\right)\right)$ by a logistic function of the following type ${ }^{42}$

$$
r\left(f s_{t} \mid \gamma, c\right)=\left[1+\exp \left(-\gamma\left(f s_{t}-c\right)\right)\right]^{-1}, \gamma>0
$$

with the credit spread and interest $r(\cdot)$ arising from financial stress, $f s_{t}$, in particular if it is rising above some threshold, $c$. For the construction of such a financial stress index, see Schleer and Semmler (2015).

This function represents roughly the function that has been observed by De Grauwe (2012) in EU data ${ }^{43}$ and can be thought of as representing the shape of financial stress that has been observed in Schleer and Semmler (2015). The interest payment rises with the shape of the function of eq. (10), first slowly, then more rapidly but it is then finally bounded.

One would expect that with less financial stress and lower interest payments on debt a higher steady state leveraging ratio is admissible. Again, debt is sustainable if the second term in eq. (9), the excess of income over spending, is equal to the first term, the interest payments on debt. ${ }^{44}$

The result of our finite horizon model as presented in eqs. (6)-(10), using our NMPC methodology, is shown in figure 8. Note that in the simulations the upper part of the trajectory is unstable and the debt to capital ratio eventually becomes unbounded.

To obtain figure 8 , we have set the macro feedback effects to be weak. ${ }^{45}$ As to the solution path for the capital stock and leveraging, figure 8 shows that lower interest payment on bonds

${ }^{39}$ See also Roch and Uhlig (2012). They include a utility loss in the welfare function which is similar to the Blanchard (1983) model and in Mittnik and Semmler (2013).

${ }^{40}$ Blanchard (2013) expresses this as multiple equilibrium dynamics: "The higher the debt, the higher the probability of default, the higher the spread on government bonds, and the harder it is for the government to achieve debt sustainability. But the adverse effects do not stop there. Higher sovereign spreads affect private lending spreads, and in turn affect investment and consumption. Higher uncertainty about debt sustainability, and accordingly about future inflation and future taxation, affects all decisions. I am struck at how limited our understanding is of these channels. Reduced form regressions of growth on debt can take us only so far. ....At high levels of debt, there may well be two equilibria, a "good equilibrium" at which rates are low and debt is sustainable, and a "bad equilibrium" in which rates are high, and, as a result, the interest burden is higher, and, in turn, the probability of default is higher. When debt is very high, it may not take much of a change of heart by investors to move from the good to the bad equilibrium." Blanchard $(2013,3)$.

${ }^{41}$ As empirics have shown, financial stress is related to high leveraging, but expresses many more factors than leveraging, see Schleer and Semmler (2015). Principle Component Analysis shows that leveraging and credit spreads are strong components. Others, for example, Gilchrist et al. (2009), have added a persistent shock to the leverage ratio to obtain a higher credit spread.

${ }^{42}$ The following function has a similar shape as the exponential function as used in (10), see Schleer and Semmler (2015). One can approximate the above function by an arctan function which has the same shape,

$$
r\left(f s_{t} \mid \gamma, c\right)=\beta \cdot \arctan \left(D_{t} / K_{t}\right) .
$$

This function is often numerically more convenient.

${ }^{43}$ Representing EU sovereign debt and bond yield data. However a similar behavior has also been observed for bond yields in the private sector, see Blanchard (2013). Others have formulated this as high and low probability of default.

${ }^{44}$ Again, sustainability is used here in the sense that the debt to capital stock ratio converges to a constant.

${ }^{45}$ Note that the credit spread is nevertheless rising due to financial market stress. Others, seeWerning (2011) and also Gavin et al. (2013) have allowed the interest rate to rise solely as a result of the central bank's monetary policy rule. They do not have credit spreads in their model. In our case the central bank can change the policy rate, but what appears to be more important is the financial market stress and credit spread. Also, they do not consider the impact of credit spread on debt sustainability. 


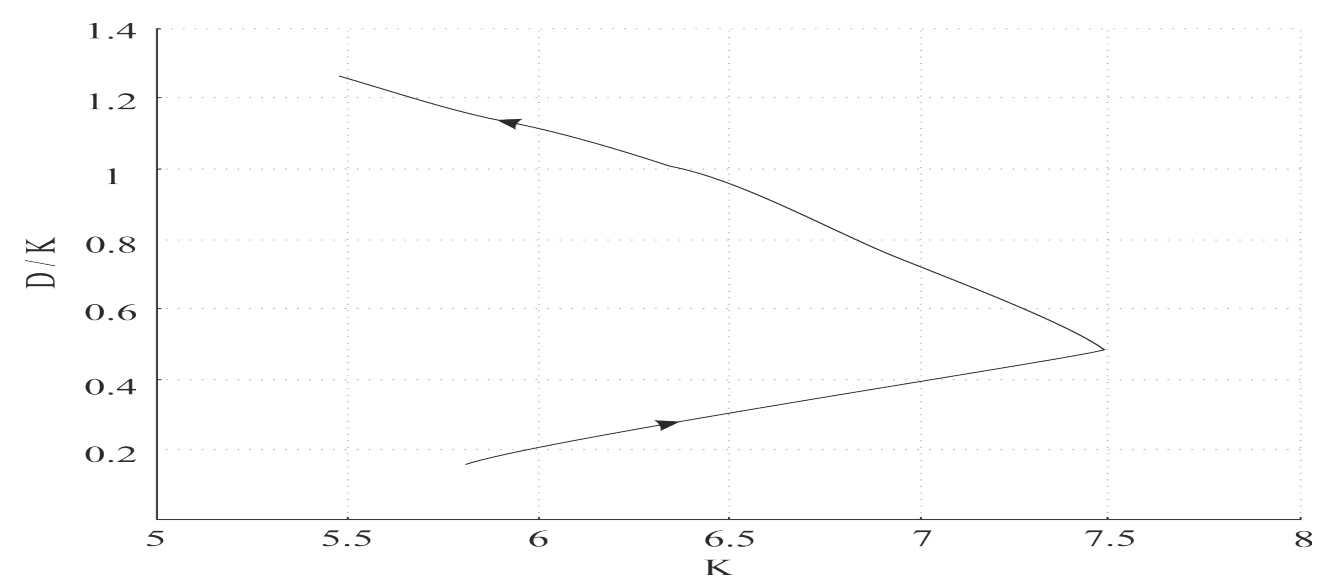

Figure 8: Dynamics with credit spread, without macro feedback loops

first admits a higher capital stock and higher leveraging. Yet, as the interest rates reach a certain threshold, we observe that with an increasing leveraging, credit risk and risk premia, capital stock stops rising but the leverage ratio is rising further. This is occurring when the credit spread is moving beyond a certain threshold. Here then finally there is unsustainable debt since the interest payment becomes higher than the surplus to service the debt, as the eq. (9) indicates. ${ }^{46}$ The contraction in output, investment and capital stock, and the rise of debt, as they are occurring at the turning point in figure 8, may also be impacted by macroeconomic feedback as they are discussed next.

\subsection{Endogenous credit spreads and strong macro feedbacks}

If feedback effects of leveraging and credit spread on investment and consumption decisions are introduced alongside endogenous risk premia and credit spreads, a slow moving debt crisis might emerge. ${ }^{47}$ Such macro feedback effects can also be interpreted as rise of macro uncertainty and its effect on investment and consumption as in Cesa-Bianchi et al. (2014). To introduce these modifications, we write our model now as:

$$
\max _{C_{t}, I_{t}, \mathcal{V}_{t}} \int_{0}^{N} e^{-r t} U\left(C_{t}, N_{t}\right) d t
$$

s.t.

$$
\begin{gathered}
\dot{N}_{t}=m^{L}\left(s_{t} U_{t}, \mathcal{V}_{t}\right)-\sigma N_{t} \\
\dot{K}_{t}=m^{B}\left(\mathcal{I}_{t}, \mathcal{B}_{t}\right)-\delta K_{t}
\end{gathered}
$$

$$
\left.\dot{D}_{t}=r\left(f s_{t} \mid \gamma, c\right)\right) D_{t}-v\left[Y_{t}^{a}-C_{t}^{a}-I_{t}^{a}-\Phi\left(s_{t}\right)\left(1-N_{t}\right)-\zeta \cdot \mathcal{V}_{t}-\varphi\left(g_{t} K_{t}\right)\right]
$$

The difference to the model variant of sect. 4.1 above is now that besides the credit spread being a nonlinear function of the debt to capital stock ratio, there is also an endogenous effect of the credit spread on demand, output and income. ${ }^{48}$ There are indeed important macroeconomic feedback mechanisms that one often can observe for an economy under financial stress, for the US

\footnotetext{
${ }^{46}$ This maybe be magnified by the reversion of the effect as mentioned before: namely the risk and risk premia rising, discount rates rising and falling (or negative) capital gains, not supporting the debt repayments any more. So debt would rise faster.

${ }^{47}$ Blanchard (2013) supports such a statement by referring to adverse macroeconomic feedback effects, see footnote 39.

${ }^{48}$ As aforementioned, Blanchard explicitly refers to those macro feedback mechanisms that not only affect the sovereign debt sustainability but also aggregate demand and output, Blanchard (2013: 3).
} 
for example, see also Hall (2011) with respect to aggregate demand, Christiano et al. (2014) with respect to a large number of macro variables, and Blanchard (2013) with respect to sovereign debt risk and its spillover to private borrowing cost.

To specify the macro feedback loops, we can make the actual consumption and investment demand depending on credit spread triggered by rising risk premia and bond yields. This would be given by:

$$
\begin{gathered}
C_{t}^{a}=f\left(r\left(f s_{t} \mid \gamma, c\right)\right) C^{o p t} \\
I_{t}^{a}=g\left(r\left(f s_{t} \mid \gamma, c\right)\right) I^{o p t}
\end{gathered}
$$

Though optimal consumption and investment plans are chosen over the planning horizon $N$, actual consumption and investment declines due to rising financial stress risk premia and credit spreads ${ }^{49}$ So, overall we may have:

$$
Y_{t}^{a}=u\left(r\left(f s_{t} \mid \gamma, c\right) Y_{t}^{o p t}\right.
$$

We can take

$$
u\left(r\left(f s_{t} \mid \gamma, c\right)\right)=\left(1-r\left(f s_{t} \mid \gamma, c\right)\right)
$$

and use the rising credit spread as self-enforcing mechanism reducing demand and output. Thus, if risk premia and credit spreads rise, and there are macroeconomic feedback loops to aggregate demand, this will reduce consumption, investment and actual output, $Y^{a}$, accompanied by a lower utilization of capacity. Thus tax revenue, as well as the net income, to service the debt, may fall. This might make then credit issuing and debt unsustainable - generating a further jump in credit spread. ${ }^{50}$

These economic outcomes seem to be less due to shocks but rather due to macroeconomic feedback loops and their adverse economic impact ${ }^{51}$ which may arise because of the following:

- If the financial market goes into distress and asset prices fall, there is the wealth effect reducing aggregate demand and both consumption and investment demand are likely to fall

- The share of households that are income and credit constrained, in the sense of Gali et al. (2004), and households that are higher leveraged and are under financial stress ${ }^{52}$ are significantly rising in a contraction period of the business cycle, see also Mittnik and Semmler (2012b)

- As the financial market forces trigger financial stress, ${ }^{53}$ the central bank may have no instruments available - or is not willing - to force the interest rate down further and/or to reduce risk premia and credit spreads, for example by purchasing sovereign bonds to drive down sovereign risk and risky bond yields ${ }^{54}$

- Given the labor market constraints, a fraction of private households could start deleveraging strongly, which reduces income and liquidity of other households and firms and might be accompanied by a debt-deflation spiral that Krugman and Eggertsson (2011) describe ${ }^{55}$

\footnotetext{
${ }^{49}$ In the local linearization version of the New Keynesian, this would just show up in the rise of the interest rate in the output equation, see Werning (2011).

${ }^{50}$ Yet one might also face insolvencies of households, firms or financial intermediaries, in the period of high financial stress, which would amplify the above described contraction.

${ }^{51}$ A systematic study of macroeconomic feedback effect, know from the history of macroeconomics, partly stabilizing partly destabilizing, are extensively discussed in Charpe et al. (2015)

${ }^{52}$ The share of those households matter, since there is empirical evidence that the drop in demand will be larger for households with larger debt and that are forced to deleverage more, see Krugman and Eggertsson (2011)).

${ }^{53}$ see Schleer and Semmler (2015) for a banking oriented stress index.

${ }^{54}$ The ECB was initially constrained by the Maastricht Treaty not to purchase sovereign bonds. Later this was relaxed by allowing it to purchase sovereign bonds on the secondary market, though there were number of programs that by-passed the Maastricht Treaty, as the recent ECB QE program with extensive bond purchases that has brought down significantly the credit spread, see sect. 4.3.

${ }^{55} \mathrm{~A}$ detailed discussion of further macroeconomic feedback effects of this type can be found in Charpe et al. (2015).
} 


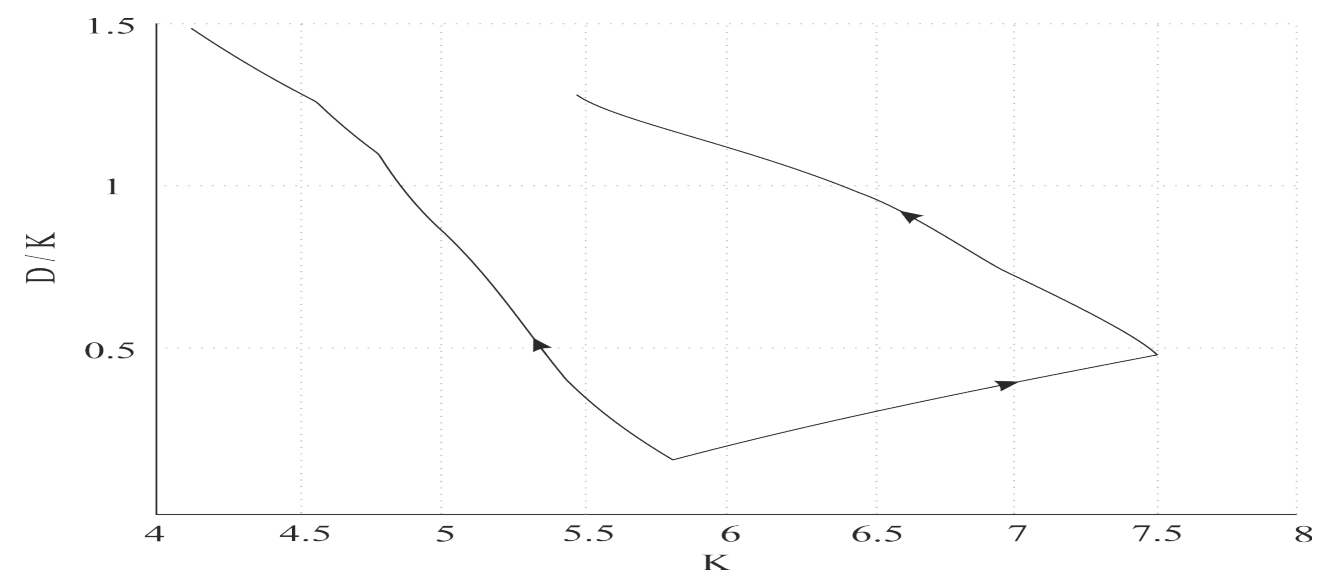

Figure 9: Debt dynamics with endogenous credit spreads and weak macro feedback loops (right trajectory), and debt dynamics with endogenous credit spreads and strong macro feedback loops (left trajectory), both starting from the initial condition $K(0)=5.8, D(0)=1.2$., both trajectories indicating instability.

- Finally, there could occur an even worse feedback: a weak financial sector, holding risky sovereign debt, may come under severe stress, because sovereign bonds may go into default and banks reduce lending to the real economy, or worse, may even default ${ }^{56}$

Whereas the first four destabilizing mechanisms have been known in the literature and are often viewed to generate a vicious cycle, the last one, which has recently been discussed, adds a more dangerous mechanism which has been called "diabolic loop". ${ }^{57}$

With these stronger macroeconomic feedback loops, we can expect, starting with a certain debt to capital stock ratio that the above feedback mechanisms lead to negative wealth effects, higher financial market stress and higher default premia, higher credit spreads and lower output leading in turn to a contraction in the utilization of the capital stock, and capital stock itself, and to an increasing leveraging ratio. ${ }^{58}$ Note that a situation is sketched here where the central bank is apparently unable or incapable to bring down sufficiently the risk premia, credit spreads and financial stress, through asset market interventions.

Figure 9 shows two solution paths for our system (11)-(18) using our NMPC procedure: the right trajectory is without (or very weak) macro feedback effects on consumption and investment demand, and the left trajectory is the solution path under the impact of strong macroeconomic feedback loops. For comparison we have included in figure 9 the solution as shown in the figure for the weak macro effects. As one can observe from the left trajectory there is now a much stronger contractionary effect as compared to the dynamics shown in the right trajectory. Yet, both solution path of both trajectories indicate that macro variables diverge and debt will not be stabilized, and a slow moving or acute debt crisis may occur.

\section{Multi-Regime VAR estimations}

Our main drivers of the debt deflation - financial stress dynamics in the above approach are output, inflation rate, credit cost and financial stress. Our model variants suggests different financial market regimes with vastly different outcomes for growth and employment. The first model variant as presented in appendix 2 predicts a tranquil financial regime with little effects from shocks. In

\footnotetext{
${ }^{56}$ See Brunnermeier and Oehmke (2013).

${ }^{57}$ See Brunnermeier and Oehmke (2013)).

${ }^{58}$ This could equivalently create a downward spiral in net worth, if the model is written in terms of net worth, as in Brunnermeier and Sannikov (2014a) and Stein (2012).
} 
contrast, the variant introduced in sect. 4.2. can be considered a financial stress regime with strong effects from shocks.

In order to estimate the relevance of these two regimes, we estimate a multi-regime vector autoregression (MRVAR). Long time series data to estimate such a higher dimensional MRVAR are not easy to obtain, so we used some proxies, particularly for credit costs. We utilize different sources for our dataset: for France and Germany we employ monthly data which runs from January 2003 until January 2013, where we use the index of industrial production for output and the HICP for the inflation rate. Both variables are taken from Eurostat and we use first differences for both. Credit cost is represented by the long-term cost of borrowing from the MFI interest rate statistics by the $\mathrm{ECB}^{59}$.

For Spain and Italy, data limitations force us to use different data sources: changes in GDP and the inflation rate are taken from the GVAR project Smith and Galesi (2014). Their data is taken from the International Financial Statistics (IFS), where GDP is a real index with base year 2005 and inflation rates represent changes in consumer prices. The data runs from 1980 until 2013 on a quarterly basis. State dependent credit cost would ideally be represented by private lending cost. However, for the period until 2003 data on private lending cost was not available. Therefore we detrended the long-term interest rate provided by Smith and Galesi (2014) (Interest Rates, Government Securities, Government Bonds concept) for the period until 2003. From 2003 until 2013 we use the MFI interest rate statistics, as described above for Germany and France, by the ECB again. Here we compute quarterly averages of the monthly interest rates provided by the ECB.

Finally, our regime defining variable is financial stress. For this we take the ZEW financial conditions index (FCI), which acts as the endogenous threshold variable in our MRVAR model and taken from Schleer and Semmler (2015). Again we use monthly data for Germany and France, while for Italy and Spain we will build quarterly averages. All empirical measures are discussed in more detail in appendix 5 .

\subsection{Methodolgy}

For our estimation we rely on a MRVAR with the FCI as an endogenous threshold variable, which allows for regime or state dependent effects of increasing financial stress.

We are using a nonlinear approach due to the shortcomings of linear VARs. In a linear model, with orthogonal impulse responses, state dependent effects of shocks are not taken into account, while impulse responses are symmetric with respect to the sign of the shock and linear in terms of their size (Koop et al. (1996)). Thus, given our model in section 4, it would be inappropriate to use a linear approach. Instead we use a multi-regime model which allows us to study regime-dependent effects. The MRVAR can be defined the following way:

$$
\mathbf{y}_{\mathbf{t}}=\mathbf{c}_{\mathbf{i}}+\sum_{j=1}^{p} A_{i j} \mathbf{y}_{\mathbf{t}-\mathbf{j}}+\epsilon_{i t} \quad \text { if } \tau_{i-1}<r_{t-d} \leq \tau_{i}
$$

where $\mathbf{y}_{\mathbf{t}}=\left(y_{1 t}, \ldots, y_{n t}\right)$ represents the endogenous variables and $\mathbf{c}_{\mathbf{i}}$ is a vector of regimedependent constants. $\tau$ stands for the threshold values and $r_{t-d}$ is the endogenous threshold variable, while $d$ is the threshold delay.

Ultimately, like in the case of a linear VAR, we are interested in the effects of a shock to a specific endogenous variable on the equation system depicted above. However, orthogonal impulse responses are not appropriate here due to the shortcomings described above. Instead one has to use generalized impulse response functions (GIRF) (see Koop et al. (1996)). GIRF allows us to take asymmetries with respect to the sign of the shock, the size of the shock and its history-dependence into account.

The GIRF work the following way: ${ }^{60}$ we split our data set into subsets of observations according to the regimes they belong to and analyze each regime on its own by taking a random starting

\footnotetext{
${ }^{59}$ https://sdw.ecb.europa.eu/browse.do?node $=2018774$

${ }^{60} \mathrm{~A}$ detailed algorithm for computing the generalized impulse responses is described in appendix 3
} 


\begin{tabular}{|c|c|c|c|c|c|c|}
\hline & $90 \%$ & $95 \%$ & $97.5 \%$ & $99 \%$ & Test Statistic & P-Value \\
\hline \hline Crit. Value MRVAR & 41.80704 & 45.72410 & 50.16905 & 53.54682 & 78.80691 & 0.0000 \\
\hline
\end{tabular}

Table 1: Spain: Test of linear VAR against MRVAR

\begin{tabular}{|c|c|c|c|c|c|c|}
\hline & $90 \%$ & $95 \%$ & $97.5 \%$ & $99 \%$ & Test Statistic & P-Value \\
\hline \hline Crit. Value MRVAR & 42.55922 & 48.53784 & 52.41626 & 57.08231 & 33.14374 & 0.37900 \\
\hline
\end{tabular}

Table 2: Italy: Test of linear VAR against MRVAR

\begin{tabular}{|c|c|c|c|c|c|c|}
\hline & $90 \%$ & $95 \%$ & $97.5 \%$ & $99 \%$ & Test Statistic & P-Value \\
\hline \hline Crit. Value MRVAR & 41.45162 & 45.98056 & 51.41440 & 57.78622 & 95.08549 & 0.0000 \\
\hline
\end{tabular}

Table 3: Germany: Test of linear VAR against MRVAR

\begin{tabular}{|c|c|c|c|c|c|c|}
\hline & $90 \%$ & $95 \%$ & $97.5 \%$ & $99 \%$ & Test Statistic & P-Value \\
\hline \hline Crit. Value MRVAR & 41.50703 & 46.01810 & 49.65223 & 56.64130 & 65.00116 & 0.00300 \\
\hline
\end{tabular}

Table 4: France: Test of linear VAR against MRVAR

value from a given regime and simulating the model with bootstrapped (regime-specific) residuals. We repeat the simulation with the same starting values and bootstrapped residuals, but we add an additional shock to one variable in period one. This procedure is then undertaken 100 - times for a given starting value and randomly drawn residuals and afterwards the average of the simulations is computed. We repeat the simulation 300 - times for each regime where histories are drawn randomly for each of them.

\subsection{Empirical Analysis}

Before estimating a MRVAR we have to test for the significance of threshold effects, where we use the test developed by Lo and Zivot (2001) to test the null hypothesis of linearity against the alternative of threshold effects. This test can be seen as a necessary condition for the appropriateness of our theoretical and empirical models. If the test fails to reject the null hypothesis of linearity, state dependencies of our economies with respect to financial market conditions would not be observed and a linear VAR would be adequate.

The threshold test was conducted with 1000 bootstrap replications for each country and a trimming value of 0.1 which guarantees that each regime contains at least $10 \%$ of all observations. The results are shown in tables (1) through (4).

As can be seen from tables (1) through (4), the tests reject the null hypothesis of linearity for all countries, but Italy. However, for reasons of comparison, we still decided to estimate a MRVAR model for Italy.

As the test for threshold effects suggested, estimating a model with two regimes, we conducted our analysis with the same settings as our threshold tests with the exception of the trimming value, which was set to 0.3 . The threshold value and threshold delay were identified by a grid search with the objective of minimizing the sum of squared residuals, where the threshold delay was set to one for all countries. The lag lengths of of our models were informed by the Schwartz criteria, which suggested a lag length of one for all countries. ${ }^{61}$.

In the next step we employed GIRF to simulate the effects of a shock to the FCI index on the change in output.The impulse responses are depicted in figures $(10(\mathrm{a}))$ through $(11(\mathrm{~b}))$.

\footnotetext{
${ }^{61}$ The estimation results are listed in appendix 7
} 


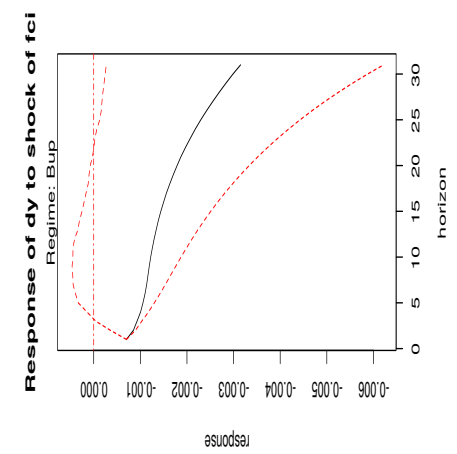

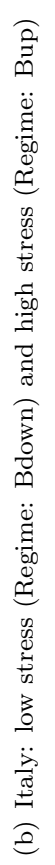

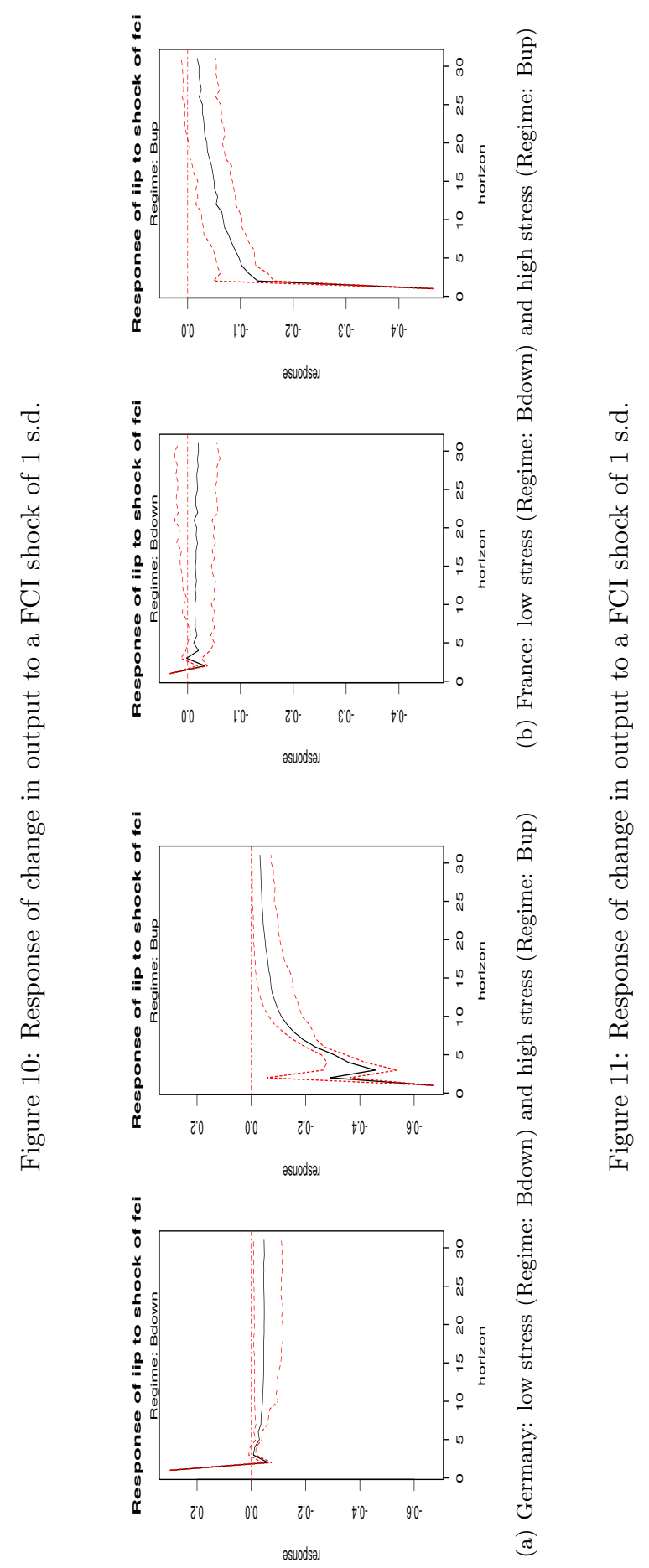


The sub-figures on the left side of figures 10(a) and 10(b) show the response of changes in output to a shock to the FCI (i.e. an increase in financial stress) for Italy and Spain during a time of tranquil financial markets. It can be seen that change in output is negative, but decreases over time and almost fades out. Thus the economies tend to recover over a period of 30 quarters.

On the other hand, an increase in financial stress during a period of tranquillity in Germany and France does not have a big impact on change in output as can be seen from figures 11(a) and 11(b). Once again, the low stress regime is depicted on the left of the two sub-figures. The effect turns negative after a short period, but remains very small.

The sub-figures on the right side of figures 10(b) through 11(b), however, show the effect of a shock to the FCI on the change of output during a time of high financial stress. It can be seen, reflecting the non-linearities of financial market shocks, that the consequences of increasing financial stress are more severe in times of financial market stress, compared with a period of tranquility in financial markets. The effect shows similar patterns for Spain, Germany, and France: While a shock to the FCI during a period of high financial stress leads to a big contraction in output in the beginning, the change in output becomes smaller as time progresses. The effect looks different for Italy: Here a shock to the FCI leads to a negative initial response of change in output, which remains negative, and becomes even stronger, as time passes on.

Thus the results of the impulse response analyses confirm our model predictions from section 4: the qualitative behaviour of changes in output due to a financial market shock is different during a time of financial stress, compared to a time of financial tranquillity. The negative response of change in output becomes much stronger in times of high financial stress, thereby increasing the strain on the economy even further.

\section{Implications for macro policies}

As we showed empirically in sect. 2 by using the GVAR approach, Europe currently faces the danger of adverse effects of debt deflation on output and employment more strongly than Japan and the US. Our study also demonstrated, though the disinflation or deflation of product prices is likely to trigger a period of recession and output decline, there are, as the model variants of sects. 4.1 and 4.2 demonstrated, additional financial risk drivers and a possible change into a high financial stress regime, with high credit costs and low credit flows, that create the danger of a protracted period of output and employment decline. This switch into a new regime is likely to be triggered and amplified by overleveraging and actual defaults, insolvencies of firms and banks, loan losses and fire sales of assets, leading to rapid credit, output and employment contractions. ${ }^{62} \mathrm{We}$ have also shown that debt stabilization might become more difficult if there are both deflationary and financial risk drivers.

As to the debt deflation spiral itself, disinflation and deflation has been built into the model variant of sect. 3, replicating roughly the empirical results of the NK literature, though in a more short cut way, in a higher dimensional macro model by using the rate of change of the inflation rate. For some countries we could replicate the fact that in the Great Recession and its aftermath prices did decline less than what had been expected given the large output and employment slacks. Our empirics of sect. 5, estimating non-linearities and asymmetries of effects of shocks in a MRVAR has also underlined the perils of debt deflation when it is coupled with an addition financial market stress in a regime of credit spread rising and reduced credit flows, entailing an output and employment decline.

When using our four dimensional MRVAR model with the financial stress as transition variable we showed empirically that there is a high risk that the vulnerability of the financial sector and financial stress may trigger a regime change in the financial market - output link. Though short term interest rates can be kept down, following the Taylor rule for the central bank, real interest rate might rise due to deflation and financial stress and credit spreads could nevertheless move up, triggering a transition to a financial crisis regime in Euro-area countries. ${ }^{63}$ What appears to

\footnotetext{
${ }^{62}$ see Borio et al. (2015))

${ }^{63}$ Many earlier NK studies often allow the interest rate to to fall through the central bank's monetary policy rule. A new type of NK literature seems to emerge that take into account the role of financial market risk for risk premia
} 
be important in this context is the degree of the financial sector's leveraging and overleveraging (see appendix 3). In fact the latter issue, as our sect. 4 shows, the rise of vulnerability of the financial sector, the decline of credit flows, and an increase of financial market stress, are important amplifying forces that also trigger adverse macro feedback loops. This then appears to become a more severe risk driver interacting with the slowly moving debt deflation process.

In this context we can spell out some implications of our modeling results for macro policies. Pursuing sovereign debt consolidation policies might work under the conditions corresponding to a normal path of the economy, such as sketched in appendix 2, and it also might temporally work under the condition shown in the right trajectory in figure 9. Yet, in a regime of high financial market stress, deflation and rising real interest rate, and a larger jump in the risk premia, with capital gains and net worth falling, the banking system under financial stress, and with central banks constrained to undertake an unconventional intervention into asset markets, the strong macro feedback loops create great challenges for fiscal consolidation policies, and they are likely not to be successful, under the condition of the left trajectory of figure 9 . In this case, output and employment multipliers are strong and are likely to trigger adverse and amplifying feedback loops.

Moreover, as appendix 2 might demonstrated, a declining credit risk and credit spreads, possibly engineered by monetary policy through quantitative easing, can reduce adverse macro feedback effects and support policies of debt sustainability output and employment growth. As recent empirical literature on EU periphery countries have shown, reducing the risk premia and credit spread appears to be an important escape route from high financial stress and default risk and re-initiating credit flows. Thus, monetary policy of quantitative easing, which was pursued in the US in the aftermath of the Great Recession, and introduced in Euro area countries with the ECB policy starting in January 2015, seems to be very important to escape from a deflationary trends and high financial stress-high credit spread regimes.

However, what might be needed is - as Brunnermeier and Sannikov (2014b) argue - a more selective monetary policy, as well as selective asset market and credit market policies to overcome regional and local bottle necks in lending and borrowing. We have shown that output and employment gaps, arising for example in financially caused recessionary periods, give rise, together with low vacancy rates, to low job finding rates and high unemployment. The decentralized matching mechanisms of the labor and credit markets in the Euro-Area economies may result in quite different success rates of aggregate policies. More specific growth and labor market policies may be appropriate. This seems to be in contrast to the observations of the policy effects in the long lasting period of output and employment decline in the US after the Great Recession, where aggregate macro policies, because of the more fluid financial, credit and labor market matching mechanisms appear to have worked better.

\section{Conclusions}

EU-area countries with large debt overhang seem to have entered a new period of disinflation, and even deflation, following the period of output and employment decline during the great recession 2007-9. We demonstrate that such disinflation and deflation leads to a rising real interest rate, exacerbating the leveraging problem, in particular during periods of low growth of real income. There appeared to be a risk of a regime shift into high financial stress and rising credit spreads, possibly accompanied by strong adverse macroeconomic feedback loops. To investigate the consequences of overleveraging and the potential for destabilizing effects from deflation and financial - and real-sector interactions we introduce first a theoretical model, and demonstrate, with the presence of regime-dependent macro feedback relations, the possibility of an unstable dynamics and downward spirals. In order to capture the heterogeneity in the Euro-area, we introduce decentralized matching mechanisms on the labor and financial markets. We might then conjecture that those dynamics are different for the Northern core countries in contrast to periphery countries.

If we admit debt overhang and disinflation and deflation, and endogenously generated credit constraints, risk premia and credit spreads, we can observe destabilizing effects in the theoretical

$\overline{\text { and credit spread, see Furlanetto et al. (2014)) }}$. 
model, with persistent contractions and no debt sustainability. Moreover, with the rise of credit and financial stress, large contractions, with protracted periods of large and persistent unemployment spells, an unsustainable debt dynamics can arise. This is likely to be exacerbated when there are significant adverse macro economic feedback effects of credit spreads and financial stress on employment, consumption, investment demand, and utilization of capacity. On the other hand, we showed that with increasing rates of inflation, low financial stress and low interest rates are conducive to deleveraging, debt sustainability and higher growth of output and employment.

Overall, as we showed, in particular southern countries need higher inflation and growth rates to overcome the debt deflation and financial stress risk drivers. Differences in the core and periphery countries need to be taken into account in particular when employment and credit policies are designed. Given the very heterogeneous matching mechanisms on the labor and credit markets, more selective policies seem to be needed.

Empirically, deflationary trends in the Euro-Area were explored with MRVAR models with regime dependent IRFs to study time series effects of risk drivers and investigated nonlinear relationships in higher dimensional regime change models where a measure of financial stress was the regime defining variable. In general, MRVARs, ${ }^{64}$ help us understand what happens in different regimes and one can observe state dependence of fiscal and monetary policy effects: one can predict a quite different impact of policies in contractions, in particular on output, employment and inflation rates as well as financial stress, as compared to expansions.

Some regime dependence of macro laws are studied in appendix 5. As we demonstrate there, using a low dimensional VSTAR method, the credit-output link, the Phillips-curve and Okun's Law are quite regime dependent and need to be looked at in a regime dependent context. As to the credit-output link, negative output or credit shocks trigger much larger negative responses to shocks in a high leveraging regime with excessive debt, as defined in appendix 4. This holds for both when GDP or credit are shocked. Similar differences can be seen for the Phillips curve and Okun's law in a period of high financial stress as compared to a low stress regime. We also show that significant differences of those macro laws can be uncovered for Southern as compared to Northern EU-area countries.

Methodological, to explore the linkages between output, inflation, labor and financial markets, we employ a new numerical solution method, called non-linear model predictive control (NMPC), to solve our model variants. We have used this new numerical procedure in macro economics as it helps to solve model variants with constraints and regime changes in finite horizon decision models. NMPC allows one to solve those model variants by providing global solutions to higher dimensional models studied and it is less constrained by the curse of dimension.

\footnotetext{
${ }^{64}$ For further results using MRVARs, see Mittnik and Semmler (2012a, 2012b, 2013), for results on VSTARs, see Schleer and Semmler (2015), and Schleer et al. (2014).
} 


\section{Appendix:}

\section{Numerical Procedure}

For the numerical solution of the optimal control problem we do not apply here the dynamic programming (DP) approach as in Ernst and Semmler (2010) or DYNARE as used to solve DSGE model. Though DP method has the advantage that a global solution to the optimal control problem can be found, by first computing an approximation to the optimal value $V$ and then the optimal control, and its time path, is computed from $V$. For a detailed description of the specifics of the DP algorithm we are using we refer to Semmler and Gruene (2004). The main disadvantage of DP, however, is that its numerical effort typically grows exponentially with the dimension of the state variable. Hence, even for moderate state dimensions it may be impossible to compute a solution with reasonable accuracy. ${ }^{65}$

A remedy to this problem can be obtained by using nonlinear model predictive control (NMPC). Instead of computing the optimal value function for all possible initial states, NMPC only computes single (approximate) optimal trajectories. In order to describe the method, let us abstractly write the optimal decision problem as

$$
\operatorname{maximize} \quad \int_{0}^{\infty} e^{-\rho t} \ell(x(t), u(t)) d t
$$

where $x(t)$ satisfies $\dot{x}(t)=f(x(t), u(t)), x(0)=x_{0}$ and the maximization takes place over a set of admissible control functions. By discretizing this problem in time, we obtain an approximate discrete time problem of the form

$$
\operatorname{maximize} \sum_{i=0}^{\infty} \beta^{i} \ell\left(x_{i}, u_{i}\right),
$$

where the maximization is now performed over a sequence $u_{i}$ of control values and the sequence $x_{i}$ satisfies $x_{i+1}=\Phi\left(h, x_{i}, u_{i}\right)$, Here $h>0$ is the discretization time step, $\beta=e^{-\rho h}$ and $\Phi$ is a numerical scheme approximating the solution of $\dot{x}(t)=f(x(t), u(t))$ on the time interval $[i h,(i+1) h]$. For details and references in which the error of this discretization is analyzed we refer to Semmler and Gruene (2004).

The idea of NMPC now lies in replacing the maximization of the infinite horizon functional (1) by the iterative maximization of finite horizon functionals

$$
\operatorname{maximize} \sum_{k=0}^{N} \beta^{i} \ell\left(x_{k, i}, u_{k, i}\right),
$$

for a truncated finite horizon $N \in \mathbb{N}$ with $x_{k+1, i}=\Phi\left(h, x_{k, i}, u_{k, i}\right)$ and the index $i$ indicates the number of the iteration, cf. the algorithm below. Note that neither $\beta$ nor $\ell$ nor $\Phi$ changes when passing from (1) to (2), only the optimization horizon is truncated.

Problems of type (2) can be efficiently solved numerically by converting them into a static nonlinear program and solving them by efficient NLP solvers, see Gruene and Pannek (2011). In our simulations, we have used a discounted variant of the MATLAB routine nmpc.m available from www.nmpc-book.com, which uses MATLAB's fmincon NLP solver in order to solve the resulting static optimization problem.

Given an initial value $x_{0}$, an approximate solution of (1) can now be obtained by iteratively solving

(2) as follows:

\footnotetext{
${ }^{65}$ Another global algorithm that works with gridding and computation of the value function and computation of the decision variables at each grid point, is used in Gavin et al. (2013), where a New Keynesian model is solved globally. They point out quite different solutions far from the steady state as compared to solutions close to the steady state. Thus, they also show that nonlinearities matter. Yet for their algorithm it also holds that there is a curse of dimension.
} 
(1) for $i=1,2,3, \ldots$

(2) solve (2) with initial value $x_{0, i}:=x_{i}$ and denote the resulting optimal control sequence by $u_{k, i}^{*}$

(3) $\quad$ set $u_{i}:=u_{0, i}^{*}$ and $x_{i+1}:=\Phi\left(h, x_{i}, u_{i}\right)$

(4) end of for-loop

This algorithm yields an infinite trajectory $x_{i}, i=1,2,3, \ldots$ whose control sequence $u_{i}$ consists of all the first elements $u_{0, i}^{*}$ of the optimal control sequences for the finite horizon subproblems (2).

Under appropriate assumptions on the problem, it can be shown that the solution $\left(x_{i}, u_{i}\right)$ (which depends on the choice of $N$ in (2) converges to the optimal solution of (1) as $N \rightarrow \infty$. The main requirement in these assumptions is the existence of an optimal equilibrium for the infinite horizon problem (1). If this equilibrium is known, it can be used as an additional constraint in (2), in order to improve the convergence properties.

However, recent results have shown that without a priory knowledge of this equilibrium this convergence can also be ensured, see Gruene and Pannek (2011)), and this is the approach we use in the computations in this paper. It should be noted that the references just cited treat averaged instead of discounted infinite horizon problems. However, the main proofs carry over to the discounted case, see Gruene et al. (2015). In any case, the solution generated by NMPC will always provide a lower bound for the true optimal solution. The procedure also allows for irregular impacts on the dynamics of the state variables and regime switches. ${ }^{6}$

\section{The basic model - normal regime}

The decentralized matching mechanisms on the labor market is as proposed in Merz (1995) and used in Ernst and Semmler (2010)). For the matching mechanisms on the credit market we assume that there is a stream of financial funds, $\mathcal{F}_{t}$, determining the supply of available funds which come from domestic savings and capital inflow. The demand for funds come from households for consumption so that consumption can be smoothed inter-temporally and there is an intermediation for funds for investment. Presuming that the households obtain funding without constraints, is an assumption in order to reduce the dimension of the system, but we have still three state variables. All variables are here in real terms.

Overall, the dynamic decision problem has three decision variables and it is subject to three dynamic constraints, one for the change in employment, a second for capital accumulation, and a third for debt accumulation:

$$
\max _{C_{t}, \mathcal{I}_{t}, \mathcal{V}_{t}} \int_{0}^{N} U\left(C_{t}, N_{t}\right) e^{-\rho t}=\int_{0}^{N}\left\{\frac{C_{t}^{1-\eta}}{1-\eta}-e N_{t}^{\chi}\right\} e^{-\rho t}
$$

s.t.

$$
\begin{aligned}
\dot{N}_{t} & =m^{L}\left(s_{t} \cdot \mathcal{U}_{t}, \mathcal{V}_{t}\right)-\sigma N_{t} \\
\dot{K}_{t} & =m^{B}\left(\mathcal{I}_{t}, \mathcal{B}_{t}\right)-\delta K_{t} \\
\dot{D}_{t} & =r D_{t}-v\left[Y_{t}-C_{t}-I_{t}-\Phi\left(s_{t}\right)\left(1-N_{t}\right)-\zeta \cdot \mathcal{V}_{t}-\varphi\left(g_{t} K_{t}\right)\right]
\end{aligned}
$$

The preferences are over consumption flows, $C$, and employment, $N$. The dynamics of eq. (22) represents the evolution of employment which is normalized to one. Equation (23) denotes the evolution of the capital stock and equation (24) represents the dynamics of aggregate debt (households and firms). ${ }^{67}$ Our debt dynamics is written here in a way which is standard if one allows for borrowing of the private (or public sector), possibly also from abroad. ${ }^{68}$ There could be a stochastic shock occurring along the path, for example represented by eq. (22) or eq. (23). Yet, we will neglect such shocks, except when it will lead to a regime change in the dynamics.

\footnotetext{
${ }^{66}$ Note that in DSGE models regime switches are also perceived as something likely to occur which some literature starts to explore now, see Farmer et al. (2009).

${ }^{67}$ We could also allow for sovereign debt here, though we do not specify what fraction of external debt is driven by households, firms or the public sector.

${ }^{68}$ see Blanchard and Fisher (1989, ch.2) and Blanchard (1983).
} 
The terms represent $C_{t}$ : aggregate consumption, $Y_{t}$ : aggregate production, $A$ : (exogenous) labor productivity, $\mathcal{F}_{t}$ : available financial funds through savings and external borrowing, $\mathcal{B}_{t}=$ $\mathcal{F}_{t}-C_{t}$ : offered bonds to firms, $D_{t}$ : the stock of external debt, $r$ : the (exogenous given) interest rate, ${ }^{69} N_{t}$ : employment and $\mathcal{V}_{t}$ : vacancies. In addition to costly search on the labor market, issuing bonds adds another cost factor to the macroeconomic resource constraint, with per-period flow costs of funds $\phi\left(g_{t} K_{t}\right)$. Whereas $D_{t}$ represents external debt, the term [.] is external borrowing ( $\left.>0\right)$ or repayment $(<0)$, in the former case used for excess spending over domestic income, and moreover $\mathcal{F}_{t}=\mu C_{t}, \mu>1$. Thus, consumption can be smoothed inter-temporally, but investment funds might be restricted. This means investment is more scrutinized through decentralized financial market matching mechanisms, ${ }^{70}$ but if there is a consumption boom, more investment funds will also be available. ${ }^{71}$

Moreover, $\Phi(s)$ is taken fixed, equal to $s=0.2$. The function $m^{L}\left(s_{t} \cdot \mathcal{U}_{t}, \mathcal{V}_{t}\right)$ in eq. (1) is a a decentralized matching function on the labor market. Given the decentralized S\&M outcome by $m^{L}\left(s_{t} \cdot \mathcal{U}_{t}, \mathcal{V}_{t}\right)$ the job finding rate of the unemployed will be $m^{L}\left(s_{t} \cdot \mathcal{U}_{t}, \mathcal{V}_{t}\right) / \mathcal{U}_{t}$ which will depend, fixing the search intensity, on the vacancies posted by firms and the unemployment rate. ${ }^{72}$ The job finding rate is thus the ratio of the numbers of new hires divided by the number of workers searching for jobs. With higher unemployment and lower vacancies the job finding rate is lower. ${ }^{73}$

On the credit market there is also a decentralized matching mechanism defined by $m^{B}\left(\mathcal{I}_{t}, \mathcal{B}_{t}\right)$, which represents the decentralized matching mechanisms, as S\&M function, for the credit market. Both, the S\&M function for the labor and for the credit markets are Cobb-Douglas, with exponents $q_{0}=0.5$ and $q_{1}=0.5$. The parameters $\sigma, \delta$ are the separation rate and depreciation rate of capital, and $v$ is our regime switching parameter which will be either 1 or 0 , depending on the degree of leverage the economy reveals.

As mentioned, in order to modelling the supply of funds, we have made the external supply of investment funds for firms a function of the supply of funds $\mathcal{F}_{t}-C_{t}$. Given then the external funding and the consumption decision, the remaining funding can be used for providing bond offering to be matched with the bond demand arising from firms ${ }^{6}$ desired investment $\mathcal{I}_{t}$. Funding for consumption will be available from domestic and external sources, but investment funding will be obtained on the credit market by the decentralized matching process on the credit market. Note that in this first step we do not have constraints on consumption smoothing.

Thus in this basic model here, we assume that consumption is a direct choice variable and investment is expressed as intended investment, $\mathcal{I}$, to be matched with the supply of bonds, the supply of funds for bonds given by $F_{t}-C_{t}$. As mentioned, this might be a reasonable assumption that allows us to work with a lower dimensional system. It also could be interpreted that the screening and monitoring of investment funding takes place more extensively than funding for optimal consumption. In the context here, consumption is only indirectly constrained, namely through the generated output, its increase is given through the accumulation of capital stock through investment.

We can solve for the basic model using our NMPC procedures. For the basic model, representing a normal situation, where we have no regime switching, the two previous scenarios of sect. 4.1 and 4.2 do not necessarily prevail if strong monetary policy action are undertaken to reduce the interest rate and the financial market stress. This could occur for example through a policy of quantitative easing, which the US Fed has exercised and on which the ECB has embarked on since the beginning of the year 2015 .

For illustrating the potential effects of such a policy we presume that the actual interest rate can be brought down to 3 percent and is kept there by the central banks monetary policy actions. As parameters for the NMPC solution we assume again: $\mu=1.3$ and $\beta=035, \rho=r=0.03$,

\footnotetext{
${ }^{69}$ Note that the interest rate could be derived from a monetary policy rule, such as the Taylor rule, as for example in Gavin et al. (2013). In the first step here we do not consider price dynamics.

${ }^{70}$ This in principle allows us to study more properly the heterogeneity of the EU-area credit market.

${ }^{71}$ This for example, was the situation in the period of great moderation in US until 2007, and in Spain, before the financial meltdown of the years 2007-9. Of course, there are likely to be constraints for households' borrowing as well.

${ }^{72}$ This gives rise to the usual Beveridge curve

${ }^{73}$ For details, including also time varying labor market participation rates, see Christiano et al. (2014)).
} 


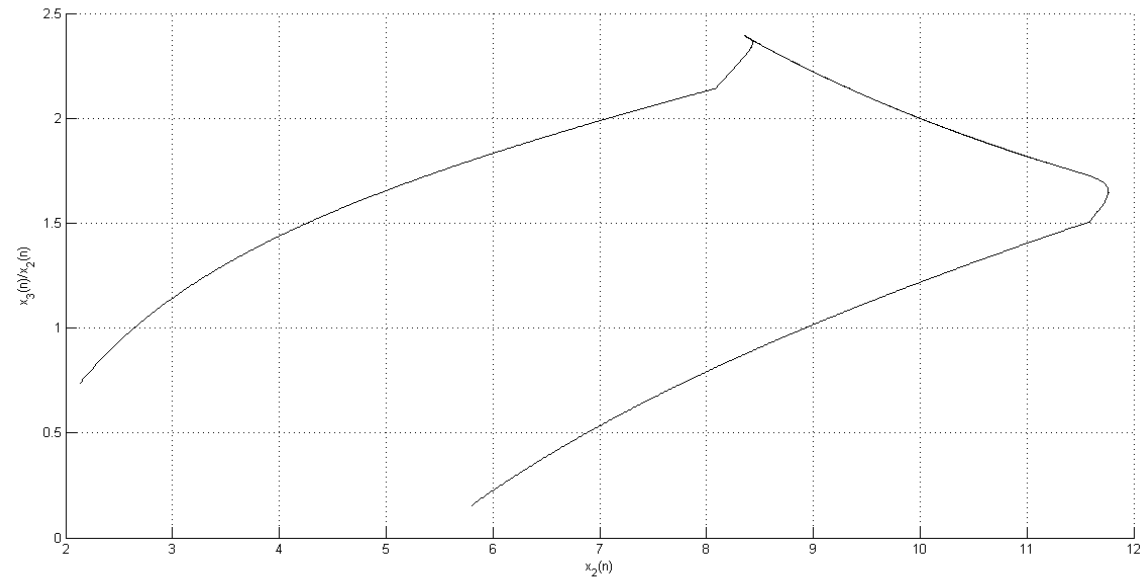

Figure 12: Dynamic solutions, horizontal axis is capital stock, vertical the debt to capital stock ratio, for $v=1$, global solution for two initial conditions, convergence to some steady state (where the trajectories merge)

$\delta=0.03, \sigma=0.04, \alpha=0.36, A=1, \xi=0.07, \chi=5, e=1$. The parameter $v$ is set to one. ${ }^{74}$

Applying the NMPC procedure, gives us a solution such as depicted in figure 12. In figure 12 the solution of eqs. (22)-(24) is shown which again represents an approximation of an infinite horizon model by a finite horizon model, using a time horizon $N=6$. As shown in figure 12 there is a steady state at about $K=8.5^{*}$ and $(D / K)^{*}=2.25$. The steady state is unique and all initial conditions for the state variables would converge toward that point.

As shown in the figure, debt could be stabilized and a steady state debt to capital ratio could be reached, see the upper converging point of the trajectories. We have chosen here parameter values which give a large steady state leveraging. Yet, we hereby have assumed that we have a regime of low interest rates which is supposed to be kept there at the low level. ${ }^{75}$ The yield on debt is $r=0.03$, equal to the discount rate, and the interest rate stays low even if leveraging is increasing and becomes larger. This success could presumably be an outcome of strong and persistent monetary policy actions.

\section{GIRF algorithm}

We follow the approach of Caggiano et al. (2014) in computing the GRIF. The algorithm has also been outlined in Semmler and Haider (2015).

1. Take the set of all observations which allows us to build $T-p+1$ histories to draw from (with replacement). The histories are split into $M$ regime-subsets $\left(\Omega_{1}, \ldots, \Omega_{M}\right)$ according to the regime they belong to.

2. Take a set of histories $\left(\Omega_{i}\right)$ out of one of the $M$ subsets from step (1) and compute the regime-dependent Variance-Covariance Matrix $\Sigma_{i}$.

3. Cholesky decompose $\Sigma_{i}$ which gives $\Sigma_{i}=C_{i} C_{i}^{\prime}$ and orthogonalize the regime-dependent residuals to get the structural shocks: $e_{i}=C_{i}^{-1} \epsilon_{i}$

4. Draw a history $\omega_{j} \in \Omega_{i}$.

\footnotetext{
${ }^{74}$ The parameter $v$ can be used as switching parameter, and $v=0$ would indicate the binding of credit constraints. This case is further explored in a companion paper, we will stay here with $v=1$.

${ }^{75}$ The interest rate could be close to the zero bound, which would make the debt sustainability and convergence even more likely.
} 
5. From $e_{i}$ draw a set of $n$ four-dimensional structural errors $e_{i}^{*}=\left(e_{i t}, \ldots, e_{i t+n}\right)$ with replacement, where the contemporaneous correlation of the structural errors is taken into account. Afterwards transform the residuals back into their reduced form representation: $\epsilon_{i}^{*}=C_{i} e_{i}^{*}$.

6. Use the history from step (4) and the structural errors from step (5) to simulate the model with the parameters from the MRVAR model.

7. Take the structural errors from step (5) and add an additional shock in period $t: e_{i}^{v}=$ $\left(e_{i t}+v_{t}, \ldots, e_{i t+n}\right)$. Then compute the reduced form errors as in (5).

8. Use the history from step (4) and the structural errors from step (7) to simulate the model.

9. Repeat steps (5) through (8) $R=100$ times and take the average of the simulations from step (6) and from step (8). The difference of the averages represents the GIRF for history $j$.

10. Repeat steps (2) through (9) $l=300$ times for regime $i$ where the histories are drawn from $\Omega_{i}$ with replacement. Take the average over all estimated $\operatorname{GIRF}^{i}\left(G I R F^{i, 1}, \ldots, G I R F^{i, l}\right)$ which represents the GIRF for regime $i$.

11. Repeat steps (2) through (10) for all regimes to get the GIRF for all $M$ regimes.

12. The confidence intervals are computed by taking the $5 \%$ and $95 \%$ percentile of the densities of the simulated GIRF $\left(G I R F^{1}, \ldots, G I R F^{l}\right)$ for each regime.

\section{Measuring excess leveraging}

Since one issue of the debt deflation is the build-up of excess debt, we here briefly want to sketch how this can be measured. Excess debt is defined as difference of actual debt and sustainable debt. ${ }^{76}$

\section{Sustainable Debt}

Stein (2012) shows how the optimal debt ratio can be derived in the simplified case of logarithmic utility. The stochastic differential equation for net worth is (A1).

$$
d X(t)=X(t)[(1+f(t))(d P(t) / P(t)+\beta(t) d t)-i(t) f(t)-c d t]
$$

$X(t)=$ Net worth, $f(t)=$ debt/net worth $=L(t) / X(t), d P(t) / P(t)=$ capital gain or loss, as stochastic, $i(t)=$ interest rate, also stochastic, $(1+f(t))=$ assets/net worth, $\beta(t)=$ productivity of capital. Hereby $c(t)=C(t) / X(t)$, consumption/net worth, $c$ is taken as fixed. Let the price evolve stochastically as

$$
d P(t)=P(t)\left(a(t) d t+\sigma_{p} d w_{p}\right)
$$

where drift a(t) will depend upon the Model I or II. The interest rate also evolves as stochastic process

$$
i(t)=i d t+\sigma_{i} d w_{i}
$$

substitute (A2) and (A3) in (A1) and derive (A4)

$$
\begin{gathered}
d X(t)=X(t)[(1+f(t))(a(t) d t+\beta(t) d t)-(i f(t) d t+c d t)]+\left[(1+f(t)) \sigma_{p} d w_{p-} \sigma_{i} f(t) d w_{i}\right] \\
d X(t)=X(t) M((t) d t+X(t) B(f(t)) \quad(A 4) \\
M(f(t))=[(1+f(t)(a(t) d t+\beta(t)) d t-(i f(t)+c)]
\end{gathered}
$$

\footnotetext{
${ }^{76}$ For details, see Schleer et al. (2014).
} 


$$
\begin{gathered}
B(t)=\left[(1+f(t)) \sigma_{p} d w_{p}-\sigma_{i} f(t) d w_{i}\right] \\
B^{2}\left((t)=\left(1+f(t)^{2} \sigma_{p}^{2} d t+f(t)^{2} \sigma_{i}^{2} d t-2 f(t)(1+f(t)) \sigma_{i} \sigma_{p} d w_{p} d w_{i}\right.\right. \\
\left.R i s k=R(f(t))=\left(\frac{1}{2}\right)\left[(1+f(t))^{2} \sigma_{b}^{2}+f(t)^{2} \sigma_{i}^{2}-2(t)(1+f(t)) \sigma_{b} \sigma_{i} \rho\right)\right]
\end{gathered}
$$

$M(f(t))$ contains the deterministic terms and $B(f(t))$ contains the stochastic terms. To solve for $X(t)$ consider the change in $\ln X(t)$ (A5). This is based upon the Ito equation of the stochastic calculus. As Stein shows using the logarithmic criterion one does not need to use dynamic programming. The expectation of $d \ln X(t)$ is $(\mathrm{A} 6)$.

$$
\begin{gathered}
d \ln X(t)=(1 / X(t)) d X(t)-\left(1 / 2 X(t)^{2}\right)(d X(t))^{2} \\
E[d(\ln X(t))]=[M((t)]-R[((t)] d t]
\end{gathered}
$$

Equ. (A6) represents a mean-variance formulation. The correlation $\rho d t=E\left(d w_{p} d w_{i}\right)$ is negative, which increase risk. $(d t)^{2}=0, d w d t=0$.

The optimal debt ratio $f^{*}$ maximizes the difference between the Mean and Risk.

$$
\begin{gathered}
f^{*}=\operatorname{argmax}[M(f(t))-R(f(t))]=[a(t)+\beta(t)-i]-\left[\left(\sigma_{p}^{2}-\rho \sigma_{i} \sigma_{b}\right)\right] / \sigma^{2} \\
\sigma^{2}=\sigma_{i}^{2}+\sigma_{p}^{2}-2 \rho \sigma_{i} \sigma_{p}
\end{gathered}
$$

On model version of Stein (2012) assumes mean reversion so that the price $P(t)$ has a trend $r t$ and a deviation $y(t)$ from it (A8). The deviation $y(t)$ follows an Ornstein-Uhlenbeck ergodic mean reverting process (A9). Coefficient $\alpha$ is positive and finite. The interest rate is the same as in model II.

$$
\begin{gathered}
P(t)=P(0) \exp [r t+y(t)] \\
d y(t)=-\alpha y(t)+\sigma_{p} d w_{p}
\end{gathered}
$$

Therefore using the stochastic calculus $a(t)$ in Model I is the first term in (A10)

$$
d P(t) / P(t)=\left(r-\alpha y(t)+\left(\frac{1}{2} \sigma_{p}^{2}\right) d t+\sigma_{p} d w_{p}\right.
$$

Substitute (A10) in (A7) and derive (A11), the optimal debt ratio in Model I.

$$
f^{*}(t)=\left[(r-i)+\beta-\alpha y(t)-\left(\frac{1}{2}\right) \sigma_{p}^{2}+\rho \sigma_{i} \sigma_{p}\right] / \sigma^{2}
$$

Hereby Stein considers $\beta(t)$ as deterministic.

Another Model on capital gains and returns presumes the price equation is (A12). The drift is $a(t) d t=\pi d t$ with a diffusion term $\sigma_{p} d w_{p}$.

$$
d P(t) / P(t)=\pi d t+\sigma_{p} d w_{p}
$$

The optimal debt ratio $f^{*}(t)$ is (A13). Again, consider $\beta(t)$ as deterministic.

$$
\begin{gathered}
f^{*}(t)=\left[(\pi+\beta(t)-i)-\left(\sigma_{p}^{2}-\rho \sigma_{i} \sigma_{p}\right)\right] / \sigma^{2} \\
\sigma^{2}=\sigma_{i}^{2}+\sigma_{p}^{2}-2 \rho \sigma_{i} \sigma_{p}
\end{gathered}
$$

Empirical measures of excess leveraging of banks can be obtained as discussed in Schleer et al. (2014). There it is shown what empirical variables are needed to compute sustainable debt and actual debt, both as normalized debt ratios. 
Measuring issues

$$
\left((r-i)+\beta-\tilde{\beta}+0.5 \sigma_{r}^{2}+\rho * \sigma_{i} * \sigma_{r}\right) / \sigma^{2}
$$

with $r=$ capital gains,$i=$ long-term government bond yield, $\beta=$ productivity of capital, $\tilde{\beta}=$ demeaned beta (beta deviation), $\sigma_{r}^{2}=$ Half of the square of the demeaned capital gain, $\bar{i}=$ demeaned interest rate, $\bar{r}=$ demeaned capital gain, $\rho=$ correlation of $i$ and $r, \sigma_{i}=$ standard deviation of interest rate, $\sigma_{r}=$ standard deviation of capital gain, $\sigma=$ risk element $=\left(\sigma_{i}+\sigma_{r}-2(\rho \bar{i} \bar{r})\right)$.

Capital gains, denoted by the variable $r$, are calculated as the percentage change in the stock market capitalization (market cap) of the bank during the period. The market cap data is given quarterly and computed as the product of the stock market price and the common shares outstanding. The common shares outstanding is the difference between issued shares and treasury shares. The market cap is subject to stock market swings. To eliminate these, and to obtain the trend of capital gains, the Hodrick-Prescott-Filter with parameter $\lambda=1600$ matched to the quarterly frequency of the data is applied. The filtered capital gain is then given by the percentage change between the year-end market caps.

The long-term government bond yield $i$ corresponds to the long-term (9/10-year) treasury yield of the country the bank is mainly situated at and is given in percent. The productivity of capital $\beta$ is calculated by dividing the bank's net income from the annual shareholders' equity for each period. More precisely, we consider the net income after preferred dividends which the bank uses to calculate its basic earnings per share. The annual shareholders' equity is thereby given as the sum of preferred stock and common shareholders equity. Once again year-end data is used. To calculate the beta deviation $\tilde{\beta}$, the difference between each period's beta from the mean beta over all periods is computed. The demeaned interest rate $\bar{i}$ and demeaned capital gain $\bar{r}$ are calculated identically.

The correlation $\rho$ of the capital gains $r$ and the interest rate $i$ is calculated over the entire period and then used as a constant value over the periods. Similarly, the standard deviations $\sigma_{i}$ and $\sigma_{r}$ of the interest rate and capital gain, are also constant over the periods. The risk element $\sigma$ of the formula is given as the sum of the standard deviations $\sigma_{i}$ and $\sigma_{r}$ deducting twice the value of the variances of the interest rate, capital gain and the correlation between them.

The actual debt ratio is calculated as the average yearly long term debt balances divided by the average yearly total assets. When both the actual and sustainable are normalized, one can take the difference of the two to obtain excess leveraging, which plays an important role in our estimation of the vulnerability of the economic sectors considered.

\section{Regime dependent macro laws}

Using two or three dimensional VARs and IRs we can estimate a small-scale macro-econometric models with multiple regimes, using vector smooth-transition auto-regressive techniques (VSTAR) and applying it to data for the US and EU country groups. But note, though the smooth transition auto-regression method (STAR) model, is able to estimate regimes and to capture different dynamic properties over time and across regimes, so far only low dimensional macro problems have been addressed. In general, regimes can be estimated through an indicator function, a Markov switching model or a STAR model (a smooth transition regression model). A specific regime can be defined by an output regime (low and high output growth rates), ${ }^{77}$ financial market regime (low and high financial market stress), ${ }^{78}$ or with respect to low and high leveraging (see Schleer et al. (2014)). We here refer to a VSTAR model, as originating in Teraesvirta and Yang (2014) and used in Schleer and Semmler (2015)). There are usually only two variables, where one variable is (an) endogenous transition variable. Thus the regime change variable can be an endogenous variable, but if it is an exogenous variable, one can employ three variables. In the estimations below, we model a special case where one transition function governs the whole VSTAR system, with an endogenous or exogenous transition variable. The transition function captures the non-linearity

\footnotetext{
${ }^{77}$ Mittnik and Semmler (2012b)

${ }^{78}$ Mittnik and Semmler (2013) and Schleer and Semmler (2015)
} 
of the transition variable with respect to the other variables of the system and, hence, looks as follows:

$$
\mathbf{g}\left(f s_{t} \mid \gamma, c\right)=\left[1+\exp \left(-\gamma\left(f s_{t}-c\right)\right)\right]^{-1}, \gamma>0
$$

which is bounded between zero and one, is monotonically increasing in $f s_{t}$, depends on the transition speed $(\gamma)$, the location parameter $(c)$ and the transition variable $\left(f s_{t}\right)$. The transition variable is either a contemporaneous or lagged variable, and can be an endogenous or exogenous variable. The parameter $\gamma$ as well as $c$ are estimated. The location parameter $c$ defines the threshold. We usually evaluate two regimes, $m=2$, with :

$$
\begin{aligned}
& T V_{t-d}<c(\text { regime below } c) \\
& T V_{t-d} \geq c(\text { regime above } c)
\end{aligned}
$$

As time series data for financial stress one can use the IMF FSI or the ZEW FCI. The latter has extensively included banking variables. The time series for the IMF FSI we are using below covers the period 1980 to 2012. The ZEW Financial Condition Indix (FCI) for the Euro- area reflects better financial sector conditions and stress. More than the FSI, the FCI focuses on the banking sector. This newly compiled data set relies on 21 financial sector series for each country. This index also tracks market volumes, particularly within the banking sector, as well as prices. For instance, the FCI includes the annual growth rate of assets over liabilities, which represents available bank collateral; the ratio of short- over long-term debt securities issued by banks; and the annual growth rate of bank lending to the private sector as well as a divers set of interest rates. Such an inclusion of banking-related factors with a strong link to the economic downturn improves the accuracy of our indices. Most of the variables are available at the country level, some are Euro-area aggregates. To account for a fairly high correlation across some variables, the ZEW FCI is established using a dynamic factor model to extract the common factor (for each country). ${ }^{79}$ Next, let us explore some non-linear macro relationships

\subsection{Regime dependent credit - output link}

As figure 13 demonstrates, for the euro area as a whole, the impulse-responses to both negative GDP and negative credit shocks differ significantly between the two regimes. As regime defining variable we have used the time series data on excess leveraging provided by Schleer et al. (2014) of the EU banking system, see appendix 4 for the measures. We define two regimes, one regime with no excess debt and another with excess debt (overleveraging) of the EU Countries' banking system. Then we study the impact of GDP shocks on credit flows in those two regimes, using regime dependent VARS and IRs.

As can in general be seen in figure 15, negative output or credit shocks trigger much larger effects in the high leveraging regime with excessive debt, both for GDP and for credit adjustments. Similarly, credit adjusts downwards much faster in response to a negative GDP shock when the Euro area is in conditions of high leveraging regime.

Similar results, not reported here, are obtained when looking specifically at peripheral (Southern) Euro-area countries. Here again, adjustments to GDP and credit are much stronger in a highfinancial stress regime than under normal borrowing conditions, leading to significant responses of both GDP and credit to a negative credit shock.

\subsection{Regime dependent Phillips Curve}

We carry out the same exercise for the Phillips curve, for the Euro-area, also distinguishing between core and periphery countries. Again, the Euro-area periphery group aggregates information for Greece, Italy, Portugal, Spain and Ireland whereas the Euro-area core group sums up unemployment and inflation data for Austria, France and Germany. ${ }^{80}$

\footnotetext{
${ }^{79}$ For a detailed description of sources and transformations of the data and variables, see Schleer and Semmler (2015).

${ }^{80}$ Note that for the subsequent exercise we take the ZEW FCI, since the IMF FSI does not cover sufficiently the EU countries of interest.
} 
$G D P$ on $G D P$

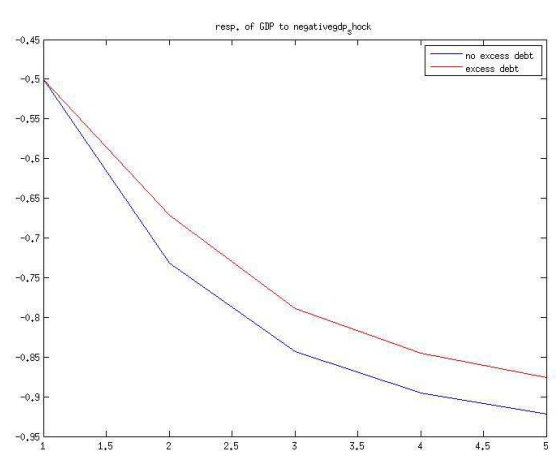

GDP on credit

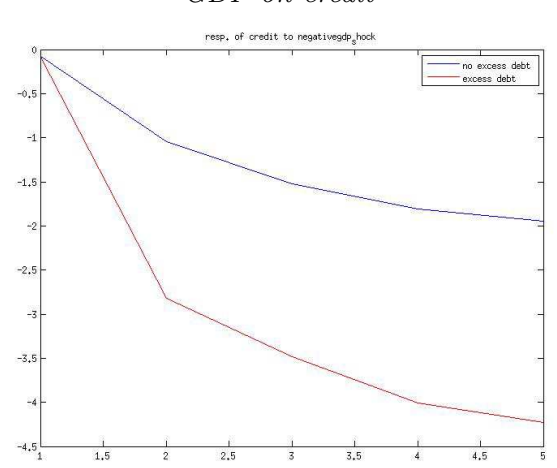

Credit on GDP

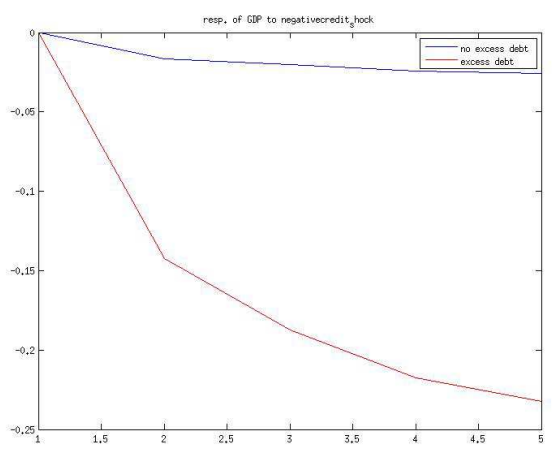

Credit on credit

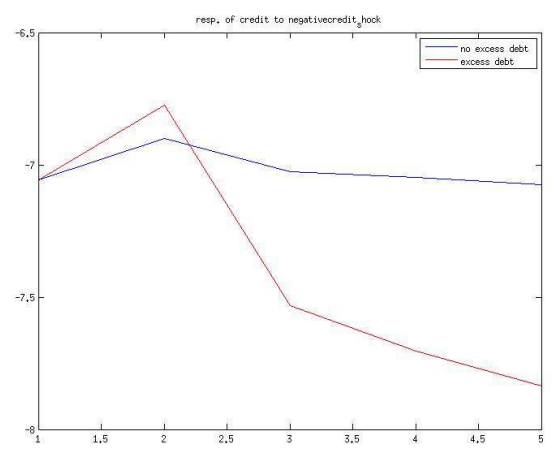

Note: The blue line represents normal financial conditions, the red line excessive debt.

Figure 13: Impulse-response functions in different financial regimes: Euro area 
Figure 14 compares the reaction of both the unemployment and the inflation rate with respect to a positive unemployment rate shock for the two regimes of financial stress. For the two different regimes Panel A depicts results for the Euro-area periphery country group whereas Panel B presents the results for the Euro-area core country group. The blue lines depict the reaction of the economy in periods of low financial stress, the green the reaction when financial stress is high.

As can be seen from the different charts, the reaction of unemployment to a adverse shock on the labor market is very similar in both regimes with unemployment increasing over the five years following the shock. Small differences exist between the two regimes in the Euro-area core country group where, notably, the unemployment rate rises further when financial stress is low. More significant are, however, the differences in inflation dynamics between the two regimes. In both country groups, inflation declines much more strongly in periods of high financial stress. Note that the disinflationary pressure is even stronger in the high financial stress regime among Euro-area core countries, highlighting one of the challenges to Euro-area periphery countries have been facing during the crisis: Despite record-high unemployment rates, inflation rates fell only very gradually such as to restore competitiveness in these countries. Our estimates reflect this strong persistence of inflation dynamics in these countries, as discussed in sects. 2 and 3.

Panel A: Euro-area periphery

Unemployment on Unemployment

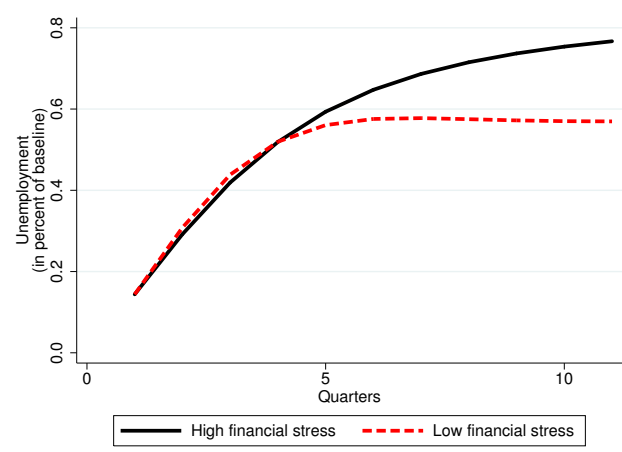

Unemployment on Inflation

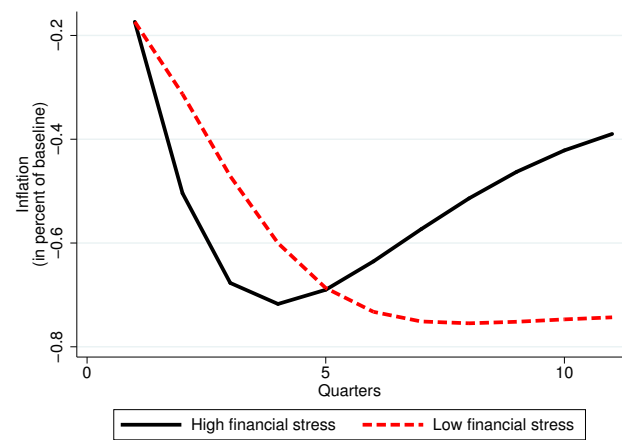

Panel B: Euro-area core

Unemployment on Unemployment

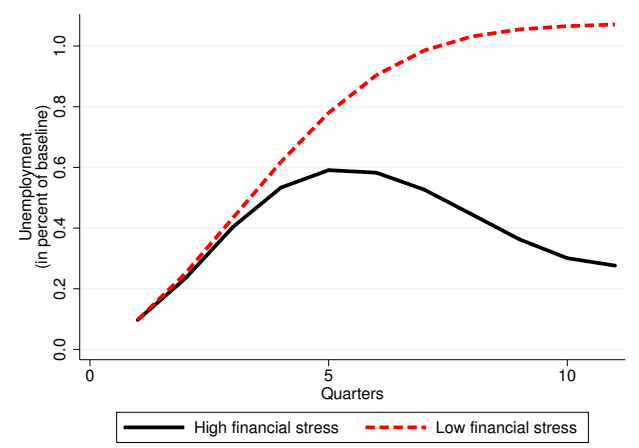

Unemployment on Inflation

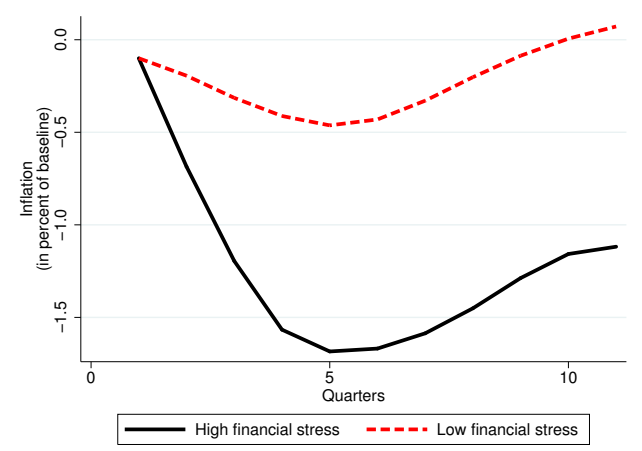

Note: Low financial stress regimes are represented in blue, high financial stress regimes in green.

Figure 14: Regime-dependent Phillips curve, ZEW-FCI as exogenous transition variable: Euro-area core vs. periphery

\subsection{Regime-dependent Okun's law}

Finally, we want to present results that also confirm some nonlinearities with respect to output growth and unemployment reduction. This relationship has been called Okun's law, that output 
growth drives employment and thus reduces unemployment. We want to explore here, again using our VSTAR method, with the ZEW FCI as transition variable, whether the unemployment reduction is also regime dependent, whereby the regime is again defined by high or low financial stress.

\section{Panel A: Euro-area periphery}

GDP on Unemployment

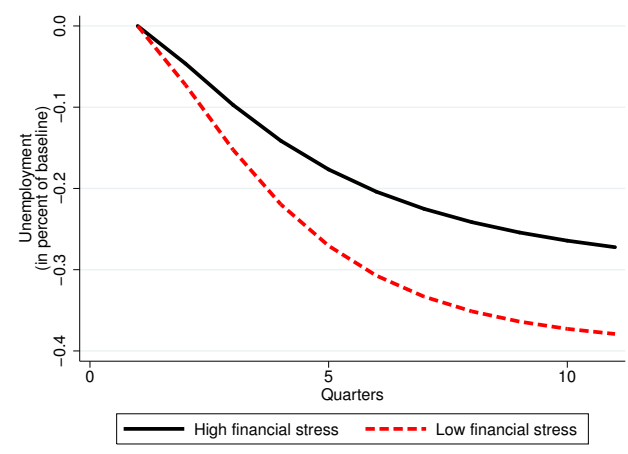

GDP on $G D P$

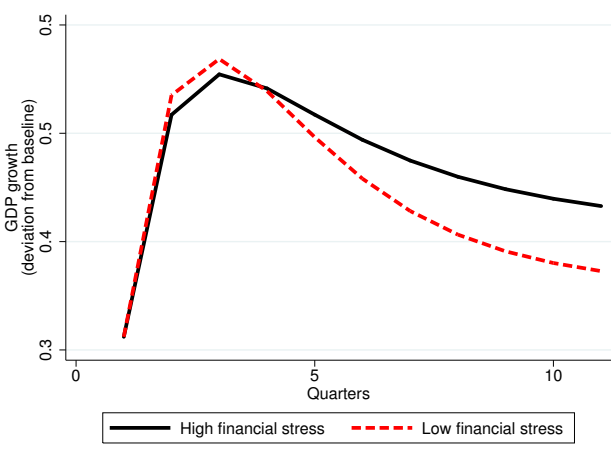

Panel B: Euro-area core

GDP on Unemployment

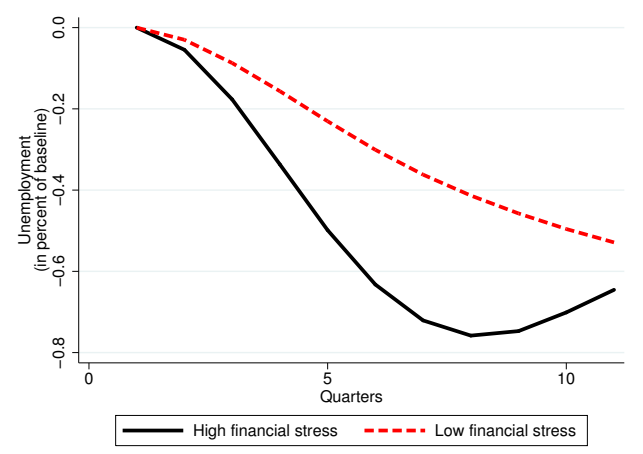

GDP on $G D P$

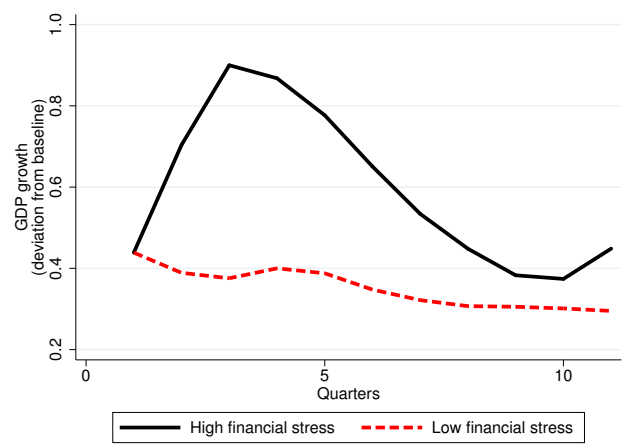

Note: Low financial stress regimes are represented in blue, high financial stress regimes in green.

Figure 15: Regime-dependent Okun's law, ZEW-FCI as exogenous transition variable: Euro area core vs. periphery

Overall, as can be seen from the two left graphs of Panel A and B of figure 15, a positive shock on output reduces the unemployment more in the periphery countries than in the core countries (see the scale), but if there is financial stress in the periphery countries, the growth has a larger success on reduction of unemployment if the growth rate is increased. Moreover, the second round effect of growth on growth is stronger in the South than in the North. This means that a higher growth rates in the Southern countries are useful targets to bring up employment in the South.

\section{Data}

We are estimating a 4 dimensional MRVAR for France and Germany with change in the index of industrial production, change in inflation rate, interest rate, and the ZEW FCI index (see Schleer et al. (2014)) as the endogenous threshold variable. The index of industrial production and the inflation rate are taken from Eurostat. The interest rate was obtained from the MFI interest rate statistics by the $\mathrm{ECB}^{81}$. The dataset for France and Germany runs from 2003 until 2013 on a monthly basis.

\footnotetext{
${ }^{81}$ https://sdw.ecb.europa.eu/browse.do?node $=2018774$
} 
A 4 dimensional MRVAR is estimated for Spain and Italy as well. Here we use the change in GDP, inflation rate, interest rate, and the ZEW FCI index as endogenous threshold variable as well. However, the sources differ: for change in GDP and inflation we use the data provided by the GVAR project (Smith and Galesi (2014)), while the GVAR data, together with the MFI interest rate statistics of the $\mathrm{ECB}^{82}$, were used for computing the interest rate. The data runs from 1980 until 2013 on a quarterly basis.

Smith and Galesi (2014) obtain their data from the International Financial Statistics (IFS) provided by the IMF. GDP is a real index with base year 2005 (concept: Gross Domestic Product, Real Index, Quarterly, $2005=100)$, while the inflation rate represents changes in consumer prices (concept: Consumer Prices, All items, Quarterly, $2005=100$ ).

For Spain and Italy we also utilize the long-term interest rate of the GVAR project (concept: Interest Rates, Government Securities, Government Bonds concept) and augment it with long-term borrowing from the MFI interest rate statistics. The interest rate was computed the following way: from 1980 until 2003 we use the GVAR data which has been detrended by a linear trend. From 2003 until 2013 the GVAR interest rate is substituted for the MFI interest rate.

\footnotetext{
${ }^{82}$ https://sdw.ecb.europa.eu/browse.do?node $=2018774$
} 


\section{References}

Arellano, C. (2008). Default risk and income fluctuations in emerging economies. American Economic Review, 98(3):690-712.

Ball, L. and Mazumder, S. (2014). A phillips curve with anchored expectations and short-term unemployment. Working Paper 20715, National Bureau of Economic Research.

Bernanke, B. S. (1983). Nonmonetary Effects of the Financial Crisis in Propagation of the Great Depression. American Economic Review, 73(3):257-76.

Binder, M. and Gross, M. (2013). Regime-switching global vector autoregressive models. Working Paper Series 1569, ECB.

Blanchard, O. (2013). Remarks on debt and macroeconomics, rethinking macroeconomic policy ii. Technical report, International Monetary Fund.

Blanchard, O. and Fisher, S. (1989). Lectures on Macroeconomics. Cambridge, Mass. and London: MIT Press.

Blanchard, O. and Leigh, D. (2013). Growth forecast errors and fiscal multipliers. Wp/13/1, IMF

Blanchard, O. J. (1983). Debt and the current account deficit in brazil. In Financial Policies and the World Capital Market: The Problem of Latin American Countries, NBER Chapters, pages 187-198. National Bureau of Economic Research, Inc.

Bohn, H. (2007). Are stationarity and cointegration restrictions really necessary for the intertemporal budget constraint? Journal of Monetary Economics, 54(7):1837 - 1847.

Borio, C., Erdem, M., Filardo, A., and Hofmann, B. (2015). The costs of deflations: a historical perspective. BIS Quarterly Review, pages 31-54.

Brunnermeier, M. K. and Oehmke, M. (2013). Bubbles, Financial Crises, and Systemic Risk. Elsevier, Amsterdam.

Brunnermeier, M. K. and Sannikov, Y. (2014a). A macroeconomic model with a financial sector. American Economic Review, 104:379-421.

Brunnermeier, M. K. and Sannikov, Y. (2014b). Monetary analysis: Price and financial stability. Technical report, Ecb Forum on Central Banking. Sintra, Portugal, 2014.

Caggiano, G., Castelnuovo, E., Colombo, V., and Nodari, G. (2014). Estimating fiscal multipliers: evidence from a nonlinear world. "Marco Fanno" Working Papers 0179, Dipartimento di Scienze Economiche "Marco Fanno".

Cesa-Bianchi, A., Pesaran, H., and Rebucci, A. (2014). Uncertainty and economic activity: A global perspective. Working Paper Series 4736, CESifo.

Charpe, M. C., Chiarella, C., Flaschel, P., and Semmler, W. (2015). Financial Assets, Debt, and Liquidity Crisis. Cambridge University Press.

Christiano, L., Eichenbaum, M., and Trabandt, M. (2014). Understanding the great recession. NBER Working Papers 20040, National Bureau of Economic Research, Inc.

Cui, W. and Radde, S. (2014). Search based endogenous illiquidity and the macroeconomy. Technical report, University College London.

De Grauwe, P. (2012). The governance of a fragile eurozone. Australian Economic Review, $45(3): 255-268$.

Ernst, E. and Semmler, W. (2010). Global dynamics in a model with search and matching in labor and capital markets. Journal of Economic Dynamics and Control, 34(9):1651-1679. 
Farmer, R. E., Waggoner, D. F., and Zha, T. (2009). Understanding markov-switching rational expectations models. Journal of Economic Theory, 144(5):1849 - 1867.

Fisher, I. (1933). The debt-deflation theory of great depressions. Econometrica, 1(4):337-57.

Flaschel, P., Kauermann, G., and Semmler, W. (2007). Testing wage and price phillips curves for the united states. Metroeconomica, 58(4):550-581.

Furlanetto, F., Gelain, P., and Sanjani, M. (2014). Output gap in presence of financial frictions and monetary policy trade-offs. Wp/14/128, IMF.

Gali, J., Lopez-Salido, J. D., and Valles, J. (2004). Rule-of-thumb consumers and the design of interest rate rules. Working Paper 10392, National Bureau of Economic Research.

Gavin, W., Richter, K. A., and Throckmorton, N. (2013). Global dynamics at the zero lower bound. Working paper, no: 2013-007a., Research Division, Federal Reserve Bank of St. Louis.

Gilchrist, S., Ortiz, A., and Zagrajsek, S. (2009). Credit risk and the macroeconomy: Evidence from an estimated dsge model. Technical report, Boston University.

Gordon, R. J. (2011). The History of the Phillips Curve: Consensus and Bifurcation. Economica, $78(309): 10-50$.

Gordon, R. J. (2016). Goodbye, golden age of growth. Technical report.

Gross, M. and Semmler, W. (2015). Convex phillips curves: Literature review a theoretical model and an empi rical analysis for the euro area. Technical report, forthcoming ECB working paper.

Gruene, L. and Pannek, J. (2011). Nonlinear Model Predictive Control,. Springer, New York, Heidelberg.

Gruene, L., Semmler, W., and Stieler, M. (2015). Using nonlinear model predictive control for dynamic decision problems in economics. Journal of Economic Dynamics and Control, 60:112 133.

IMF (2015). Credit expansion in emerging markets: Propeller of growth? Wp/15/212.

Jimeno, J. F. (2015). Long-lasting consequences of he european crisis. Working Paper 1522, Banco de Espana.

Keen, B. and Wang, Y. (2007). What is a realistic value for price adjustment costs in new keynesian models? Applied Economics Letters, 14(11):789-793.

Keynes, J. M. (1936). The General Theory of Employment, Interest and Money. Macmillan.

Koop, G., Pesaran, M. H., and Potter, S. M. (1996). Impulse response analysis in nonlinear multivariate models. Journal of Econometrics, 74(1):119-147.

Krugman, P. and Eggertsson, G. B. (2011). Debt, Deleveraging and the Liquidity Trap. 2011 Meeting Papers 1166, Society for Economic Dynamics.

Lo, M. C. and Zivot, E. (2001). Threshold cointegration and nonlinear adjustment to the law of one price. Macroeconomic Dynamics, 5:533-576.

Lo, S. and Rogoff, K. (2015). Secular stagnation, debt overhang and other rationales for sluggish growth, six years on. Working Paper 482, BIS.

Marglin, S. A. (2009). The general theory without rigid prices and wages. Technical report, Harvard University.

McKinsey (2015). Debt and (not much) deleveraging. Technical report. 
Merz, M. (1995). Search in the labor market and the real business cycle. Journal of Monetary Economics, 36(2):269-300.

Mittnik, S. and Semmler, W. (2012a). Estimating a banking- macro model for europe using a multi-regime var. Ssrn paper.

Mittnik, S. and Semmler, W. (2012b). Regime dependence of the fiscal multiplier. Journal of Economic Behavior \&s Organization, 83(3):502 - 522. The Great Recession: motivation for re-thinking paradigms in macroeconomic modeling.

Mittnik, S. and Semmler, W. (2013). The real consequences of financial stress. Journal of Economic Dynamics and Control, 37(8):1479 - 1499. Rethinking Economic Policies in a Landscape of Heterogeneous Agents.

Roch, F. and Uhlig, H. (2012). The dynamics of sovereign debt crises and bailouts. working paper, University of Chicago.

Rudebusch, G. D. and Svensson, L. E. O. (2002). Eurosystem monetary targeting: Lessons from U.S. data. European Economic Review, 46(3):417-442.

Schleer, F. and Semmler, W. (2015). Financial sector and output dynamics in the euro area: Non-linearities reconsidered. Journal of Macroeconomics, 46:235 - 263.

Schleer, F., Semmler, W., and Illner, J. (2014). Overleveraging in the banking sector: Evidence from europe. Technical Report 14-066, ZEW - Centre for European Economic Research Discussion Paper.

Schorfheide, F. (2005). Learning and monetary policy shifts. Review of Economic Dynamics, 8(2):392 - 419. Monetary Policy and Learning.

Semmler, W. and Gruene, L. (2004). Asset pricing with delayed consumption decisions. Computing in Economics and Finance 2004 59, Society for Computational Economics.

Semmler, W. and Haider, A. (2015). The perils of debt deflation in the euro area - a multi regime model. Empirica, forthcoming.

Smith, L. and Galesi, A. (2014). Gvar toolbox 2.0. Technical report.

Stein, J. L. (2012). Stochastic Optimal Control and the U.S. Financial Debt Crisis. Springer: New York.

Summers, L. H. (2014). U.S. Economic Prospects: Secular Stagnation, Hysteresis, and the Zero Lower Bound. Business Economics, 49(2):65-73.

Teraesvirta, T. and Yang, Y. (2014). Linearity and misspecification tests for vector smooth transition regression models. CREATES Research Papers 2014-04, School of Economics and Management, University of Aarhus.

Tobin, J. (1987). Unemployment, interest, deficit and money. MIT Press, Cambridge, MA.

Wasmer, E. and Weil, P. (2004). The macroeconomics of labor and credit market imperfections. American Economic Review, 94(4):944-963.

Werning, I. (2011). Managing a liquidity trap: Monetary and fiscal policy. Working Paper 17344, National Bureau of Economic Research. 